AWARD NUMBER: W81XWH-13-1-0268

TITLE: Advancing the capabilities of an authentic ex vivo model of primary human prostate cancer

PRINCIPAL INVESTIGATOR: Sophia L. Maund, Ph.D.

CONTRACTING ORGANIZATION: LELAND STANFORD JUNIOR UNIVERSITY Stanford, CA 94305

REPORT DATE: October2014

TYPE OF REPORT: Annual

PREPARED FOR: U.S. Army Medical Research and Materiel Command Fort Detrick, Maryland 21702-5012

DISTRIBUTION STATEMENT: Approved for Public Release;

Distribution Unlimited

The views, opinions and/or findings contained in this report are those of the author(s) and should not be construed as an official Department of the Army position, policy or decision unless so designated by other documentation. 


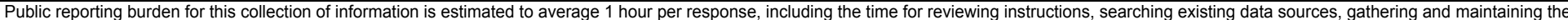

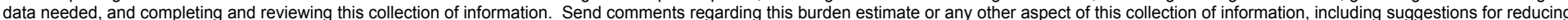

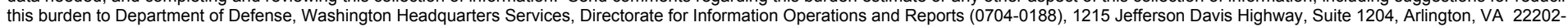

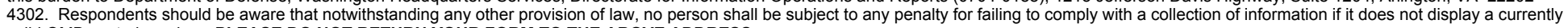
valid OMB control number. PLEASE DO NOT RETURN YOUR FORM TO THE ABOVE ADDRESS.

\begin{tabular}{l|l}
$\begin{array}{l}\text { 1. REPORT DATE } \\
\text { OCtober 2014 }\end{array}$ & $\begin{array}{l}\text { 2. REPORT TYPE } \\
\text { Annual }\end{array}$ \\
\hline 4. TITLE AND SUBTITLE &
\end{tabular}

4. TITLE AND SUBTITLE

Advancing the capabilities of an authentic ex vivo model of primary human prostate cancer

3. DATES COVERED
30 Sep $2013-29$ Sept 2014
5a. CONTRACT NUMBER

5b. GRANT NUMBER

W8 1XWH-13-1-0268

5c. PROGRAM ELEMENT NUMBER

6. AUTHOR(S)

Sophia L. Maund

5d. PROJECT NUMBER

5e. TASK NUMBER

5f. WORK UNIT NUMBER

E-Mail: smaund@stanford.edu

7. PERFORMING ORGANIZATION NAME(S) AND ADDRESS(ES)

Leland Stanford Junior University, The

450 Serra Mall

Stanford CA 94305-2004

9. SPONSORING / MONITORING AGENCY NAME(S) AND ADDRESS(ES)

10. SPONSOR/MONITOR'S ACRONYM(S)

U.S. Army Medical Research and Materiel Command

Fort Detrick, Maryland 21702-5012

11. SPONSOR/MONITOR'S REPORT

NUMBER(S)

\section{DISTRIBUTION / AVAILABILITY STATEMENT}

Approved for Public Release; Distribution Unlimited

\section{SUPPLEMENTARY NOTES}

\section{ABSTRACT}

We have begun to optimize and characterize the novel "tissue slice culture" (TSC) model for benign and primary human prostate cancer (PCa) of different Gleason grades. Under optimized culture conditions, TSCs authentically recapitulate the cellular and molecular heterogeneity of the human tissue for up to 5 days in culture. They also exhibit androgen-dependence and can be used to evaluate drug efficacy and specificity in vitro. Results suggest that the TSC system addresses several deficiencies of current pre-clinical models and is a more authentic and clinically relevant model for human PCa. We have begun to combine the TSC model with the in vivo tumorgraft model in which human tissue slices are implanted under the renal capsules of immune-deficient mice. Culturing tissue slices for 3-4 days pre-implantation not only relieves time constraints, but it also provides an opportunity for experimental manipulation.

\section{SUBJECT TERMS}

Prostate cancer, tissue slice culture, ex vivo, pre-clinical model

\begin{tabular}{|c|c|c|c|c|c|}
\hline \multicolumn{3}{|c|}{ 16. SECURITY CLASSIFICATION OF: } & \multirow{2}{*}{$\begin{array}{l}\text { 17. LIMITATION } \\
\text { OF ABSTRACT } \\
\text { UU }\end{array}$} & \multirow{2}{*}{$\begin{array}{l}\text { 18. NUMBER } \\
\text { OF PAGES } \\
\qquad 43\end{array}$} & \multirow{2}{*}{$\begin{array}{l}\text { 19a. NAME OF RESPONSIBLE PERSON } \\
\text { USAMRMC } \\
\text { 19b. TELEPHONE NUMBER (include area } \\
\text { code) }\end{array}$} \\
\hline $\begin{array}{l}\text { a. REPORT } \\
\text { U }\end{array}$ & $\begin{array}{l}\text { b. ABSTRACT } \\
U\end{array}$ & $\begin{array}{l}\text { c. THIS PAGE } \\
\text { U }\end{array}$ & & & \\
\hline
\end{tabular}


1. Introduction.......................................................1

2. Keywords.......................................................1

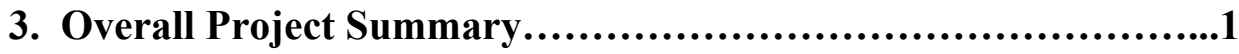

4. Key Research Accomplishments................................8

5. Conclusion.........................................................8

6. Publications, Abstracts, and Presentations..........................9

7. Training and Professional Development............................9

8. Other Achievements...........................................11

9. References..........................................................11

10. Appendices........................................................13 


\section{INTRODUCTION}

Current pre-clinical models of prostate cancer (PCa) lack many critical biological and physiological aspects of the human disease (1). Cell lines lack the native cellular heterogeneity and architecture of the benign and malignant prostate, while mouse models mimic only certain subsets of human disease states. The objective of our proposed research is to optimize, characterize, and validate a more realistic model of PCa called tissue slice culture (TSC). We take 8-mm cores of benign and malignant human tissue from prostatectomy specimens and generate 300 - $\mu$ m consecutive slices with a Krumdieck microtome (2). Slices are cultured under defined conditions to optimize viability and extend longevity. The aims of our project are to 1) optimize PCa TSC of different Gleason grades, 2) validate the TSC system as an authentic model of $\mathrm{PCa}$, and 3 ) interrogate applications of the novel in vitro TSC model of PCa.

\section{KEYWORDS}

Prostate cancer, tissue slice culture, ex vivo, pre-clinical model

\section{OVERALL PROJECT SUMMARY}

Current models do not accurately depict low risk (Gleason grade 3) and high risk (Gleason grades 4/5) primary human PCa (1). Such models are needed because treatment outcomes vary drastically between low- and high-risk PCa. Our first aim was to optimize PCa TSC of different Gleason grades (months 1-6). Our specific tasks were to (a) perform dose-response and time-course experiments with R1881 for PCa TSC of different Gleason grades, (b) test additional compounds for increased TSC longevity, (c) alter tissue slice acquisition strategies for increased TSC longevity, and (d) analyze lowgrade (Gleason grade 3) PCa TSC maintenance compared to high-grade (Gleason grade 4 or 5) over time. We have completed most of (a) and (d) of this aim, which has increased TSC longevity to sufficiently enable work under Aims 2 and 3.

(a) Using 3 slices each from 5 benign and 3 malignant specimens (grade 3 or 4), we performed dose-response and time-course experiments in complete PFMR4A medium with 0 (vehicle control), 10,50 , or $100 \mathrm{nM}$ of the synthetic hormone R1881. We left out the proposed $20 \mathrm{nM}$ dose since we don't always obtain enough slices from a given specimen to accommodate all of the proposed doses. We changed the media daily and stored conditioned media at $-80^{\circ} \mathrm{C}$ every day for $2-7$ days. We fixed tissue slices on days 0 (control), 2, 3, 4, 5, and/or 7 in 10\% buffered formalin for paraffin embedding and evaluated their histology by hematoxylin and eosin (H\&E) staining. Slices treated with the vehicle control (no R1881) exhibited areas of luminal degeneration by day 2, and histology worsened over time. Tissue slice histology improved with increasing doses of R1881 up to $50 \mathrm{nM}$, and it reflected that of the parent tissue (day 0) for up to 5 days in culture (Appendix 1, Figures 2, 6, \& S3) (2). There was no improvement in histology over time with $100 \mathrm{nM}$ $\mathrm{R} 1881$ (Figure 1). Although $50 \mathrm{nM}$ is a super-physiological dose compared to the natural levels of dihydrotestosterone acting in vivo, R1881 is often used in cell culture because of its increased stability. However, little is known about hormone dynamics in the context of organotypic culture. Two cases of benign and grade $3 \mathrm{PCa}$ were cultured for 7 or 14 days in 


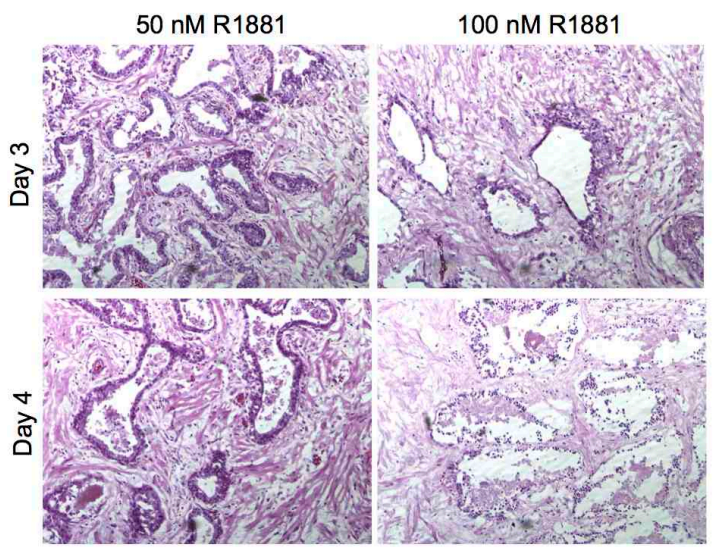

Figure 1. H\&E staining shows that benign TSCs cultured in complete PFMR4A with $50 \mathrm{nM}$ R1881 exhibit better histology than those cultured with $100 \mathrm{nM}$ R1881.

A

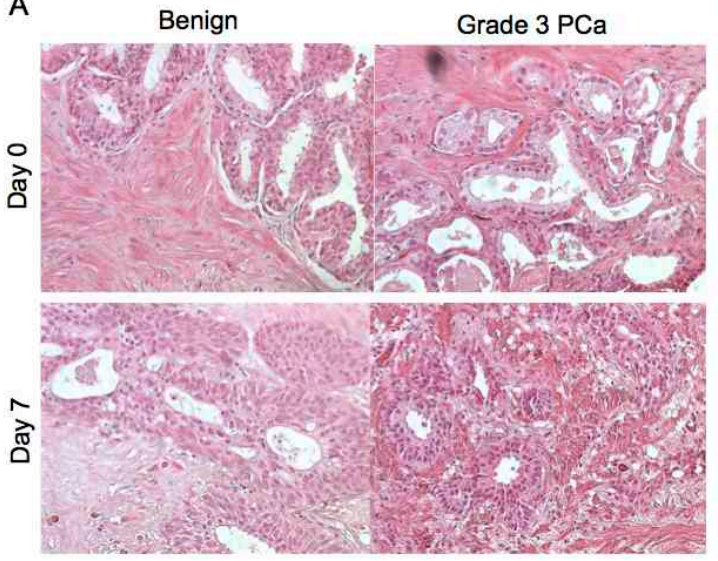

the presence of $50 \mathrm{nM} \mathrm{R} 1881$, but there was histological evidence of overall tissue degeneration at these later time points (Figure 2).

In addition to evaluating histology by H\&E, we performed immunohistochemistry (IHC) for markers of proliferation (Ki67) and apoptosis (Cleaved Caspase 3) on the aforementioned slices from day 0 and day 5 in culture. This confirmed the histological results suggesting that the day 5 TSCs are viable for 5 days in culture in the presence of $50 \mathrm{nM}$ R1881. The numbers of Ki67-positive

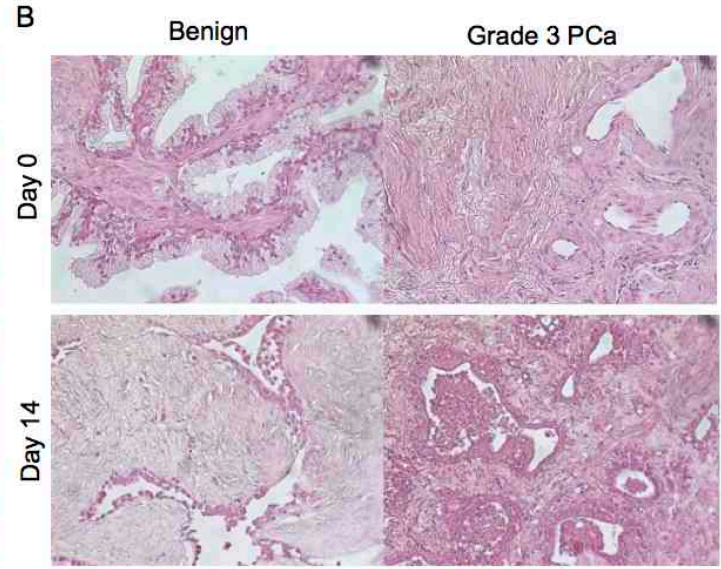

Figure 2. H\&E staining shows that histology of day 7 and day 14 TSCs do not recapitulate that of the parent (day 0 ) tissue.

and Cleaved Caspase 3-positive cells were blindly counted from 3 to 6 random 40x fields of view from each of 3 tissue slices per experimental condition, and the average percent IHCpositive cells per field was quantified. While there was an increase in Ki67-positive cells in the cancer slices compared to the benign slices as expected, there were no significant differences in the percent of Ki67-positive cells in the day 0 slices compared to the day 5 TSCs in both benign and cancer slices (Appendix 1, Figure 3) (2). Furthermore, there was no evidence of apoptosis in any of the day 0 or day 5 TSCs based on Cleaved Caspase 3 staining (Appendix 1, Figure 3) (2).

The lactate dehydrogenase (LDH) assay is one of the most widely used assays for quantifying cytotoxicity in organotypic cultures. We performed LDH assays as well as Live/Dead assays to quantify cytotoxicity and viability of benign and malignant TSCs cultured in triplicate with 0 (vehicle control) or $50 \mathrm{nM}$ of R1881 over time. For the LDH assays, conditioned medium was collected on days 2, 3, 4, and 5 from wells containing one slice each. Pilot LDH assays revealed that day $1 \mathrm{LDH}$ activity is invariably high regardless of culture condition or tissue type, likely due to surface damage from cutting. Therefore, we excluded day 1 time points from our cytotoxicity assays while the tissue recovered from slicing. Conditioned media were spun down and stored at $-80^{\circ} \mathrm{C}$ until all time points were collected. The Cytotoxicity Detection Kit Plus (Roche) was used to measure LDH activity as directed, and colorimetric absorbance readouts were normalized to the weights in 


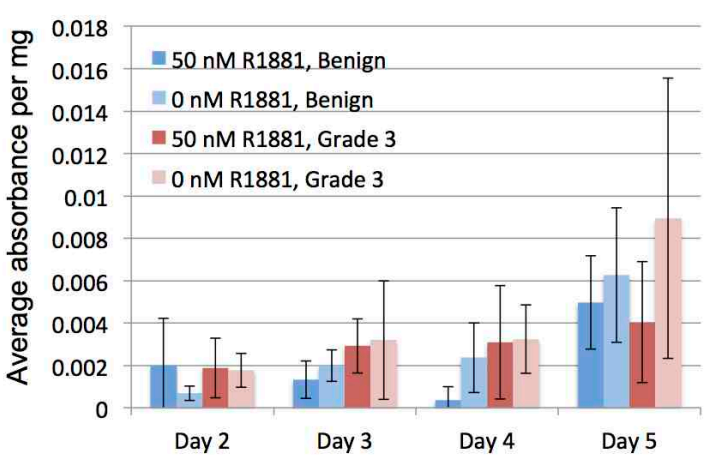

Figure 3 . LDH cytotoxicity assay on conditioned media from benign and grade $3 \mathrm{PCa}$ TSCs over time.

milligrams of the respective tissue slices to account for minor size differences among slices. Results showed minor, non-significant increases in LDH activity in TSCs cultured in the absence of R1881 over time compared to $50 \mathrm{nM}$ R1881 in both benign and malignant TSCs (Figure 3). This insignificant trend was reflected in the H\&E staining on day 5 (Appendix 1, Figure 6). LDH activity of benign and cancer TSCs rose slightly on Day 5 in culture, but not to a significant extent (Figure 3).

The Live/Dead assay (Invitrogen) is a semi-qualitative assay for viability and cytotoxicity in cell cultures, but its use with TSC-like systems has yet to be reported. It was used to evaluate viability and cytotoxicity in benign and grade $3 \mathrm{PCa}$ TSCs in the presence (50 $\mathrm{nM}$ ) or absence (vehicle control) of R1881, as described under Aim 2. We discontinued use of this assay due to the ambiguity of its qualitative results in our 3-dimensional TSCs. In addition, we had hoped to be able to use this assay repeatedly on the same slices over time in culture, but the slices did not seem to survive in culture after one time point. Nevertheless, the combination of quantitative and qualitative data from the H\&E staining, IHC for Ki67 and Cleaved Caspase 3, and LDH assays sufficiently indicated viability in benign and PCa TSCs for up to 5 days in culture.

(d) Gleason grade 5 prostatectomy specimens are not as readily available as grade 3 or 4 specimens, but we have so far successfully cultured benign and malignant slices from one case in complete PFMR4A medium with $50 \mathrm{nM}$ R1881. Day 0 and day 5 slices were evaluated by $\mathrm{H} \& \mathrm{E}$ staining and IHC for AMACR, p63, and CK5 to verify benign and cancer TSCs. Day 5 TSCs accurately recapitulated the day 0 Gleason grade 5 histology, which together with the rest of the data from Aim 1 suggests that our optimized culture conditions maintain both high-grade and low-grade PCa for up to 5 days (Appendix 1, Figure 2) (2). We will continue to characterize the viability of high-grade PCa TSCs as proposed as cases become available.

Our second aim was to validate the TSC system as an authentic model of PCa (months 4-12). The tasks under Aim 2 are to (a) assess over 5 days the cellular composition of PCa TSCs compared to that of the parent tissue, (b) characterize expression in TSCs of protein variations common in human $\mathrm{PCa}$, and (c) evaluate the response of TSCs to androgen ablation to test whether they recapitulate in vivo responses. We have completed most of each of these tasks.

(a) In 3 benign and malignant replicates from each of 3 prostates, we cultured one slice in optimized medium for 5 days and immediately processed an adjacent "day 0" slice for formalin-fixation and paraffin-embedding (FFPE). We performed IHC for a panel of lineage-specific markers of the various cell types within the human prostate in $5-\mu \mathrm{m}$ sections from day 0 slices (the parent tumor) and day 5 slices (Appendix 1, Figure 4) (2). The basal epithelial cell marker (p63) was present in a single layer in benign glands but was absent from malignant glands as expected, while cytokeratin 18 (CK18) was present in both benign luminal epithelia and cancer, as appropriate. Smooth muscle $\alpha$-actin (SMA) was 
present throughout the stroma as expected in both benign and cancer tissues. CD31 staining of endothelial cells showed evidence of vasculature in the stroma, more so in regions of cancer as has been previously observed (3). CD68 is a cell surface glycoprotein expressed by macrophages and monocytes, and its increased presence in cancer compared with benign tissue reflects an inflammatory phenotype common to PCa (4). Finally, a marker for neuroendocrine cells, synaptophysin, was expressed in distinct cells within the basal cell layer in the benign tissue and in sporadic cancer cells as expected (Appendix 1, Figure 4) (2). Overall, these results demonstrate that benign and cancer tissue slices cultured for 5 days in our system retain much of the cellular complexity and heterogeneity of native tissues, validating the fidelity of the TSC model to the human prostate.

(b) In the same specimens of benign and PCa used in task (a), we next characterized the expression by IHC of protein biomarkers that are differentially expressed in human PCa (Appendix 1, Figure 5) (2). The AMACR/p63/CK5 triple stain, used to confirm the presence of $\mathrm{PCa}$ in clinical specimens, distinguished regions of benign and malignant tissue in TSCs. The TMPRSS2-ERG gene fusion, occurring in $\sim 40 \%$ of prostate tumors, leads to androgen-driven upregulation of the ERG transcription factor (5). Using ERG expression as a surrogate marker for the TMPRSS2-ERG fusion ( 6 ), we identified PCa specimens that expressed ERG but observed that ERG expression was reduced in the TSCs after 5 days in culture. Although it is possible that androgen signaling is less robust in TSCs, TMPRSS2 expression was well maintained at Day 5. Androgen receptor (AR) expression was detected in both benign and PCa-native tissues and in TSCs after 5 days in culture. PTEN was identified in both benign and $\mathrm{PCa}$ specimens but to a somewhat lesser extent in $\mathrm{PCa}$, which may be due to haploinsufficiency $(7,8)$. Both benign and PCa TSCs maintained the PTEN expression of the native tissues after 5 days in culture. Prostate-specific membrane antigen (PSMA) was detected in benign and malignant glands as expected in both the native tissue and in TSCs after 5 days (9). In both the native tissue and the Day 5 TSCs, E-cadherin was expressed at the cell membrane of benign epithelial cells but exhibited more diffuse cytoplasmic staining in the PCa cells as expected (10). Overall, the fidelity of protein expression patterns in TSCs to the native tissues together with their cellular and structural fidelities show that the TSC model uniquely recapitulates prostate biology on structural, cellular, and molecular levels (Appendix 1, Figure 5) (2). We were able to quickly verify the spatial co-expression of the proteins via IHC, and so we did not evaluate any of them using immunofluorescence or confocal microscopy as initially proposed.

(c) In order to further evaluate the authenticity of the TSC model, the response of TSCs to androgen ablation was assessed. We obtained benign and grade $3 \mathrm{PCa}$ tissue slices from 3 prostatectomy specimens and cultured them for 5 days in the presence or absence of androgen (50 nM R1881) before processing for FFPE. Day 0 tissue was processed for FFPE immediately post-slicing. Upon histological evaluation by H\&E staining after 5 days in culture, there was evidence of ductal degeneration in regions of both benign and cancer TSCs in the absence of androgen (Appendix 1, Figure 6) (2).

We used IHC to further investigate the effects of androgen ablation on TSCs. After 5 days, evidence of proliferating cells (Ki67-positive) decreased and evidence of apoptotic cells (Cleaved Caspase 3-positive) increased in both benign and cancer TSCs in the absence of androgen (Appendix 1, Figure 6) (2). Quantification of the percent positively stained nuclei from six random 40x fields (average of 90 nuclei per field) from each of three tissue slices per condition confirmed statistically-significant increases in apoptotic cells in benign 
and PCa TSCs in the absence of androgen. There was a statistically significant reduction in Ki67-positive cells in PCa but not benign TSCs in the absence of androgen. Furthermore, intensity of PSA, an androgen-regulated gene, diminished in both benign and cancer TSCs as expected (Appendix 1, Figure 6) (2).

Instead of performing LDH assays for cytotoxicity (due to the insignificant results obtained in Aim 1), we performed MTS viability assays on benign and PCa slices cultured in the absence and presence of R1881. Results showed a statistically significant reduction of viability in benign TSCs but not cancer after 5 days in the absence of androgen (Appendix 1, Figure 6) (2). However, there is likely a heterogeneous response to androgen ablation among the epithelial and stromal cell types in both benign and cancer TSCs, as the $H \& E$ results suggested, which is not necessarily reflected by the MTS assay.

We also performed the semi-quantitative Live/Dead assay in benign and PCa TSCs cultured in the presence $(50 \mathrm{nM})$ or absence (vehicle control) of R1881. After five days in culture, slices were incubated in PBS with the ethidium homodimer-1 and calcein AM reagents that emit red fluorescence in dead cells and green in viable cells, respectively.
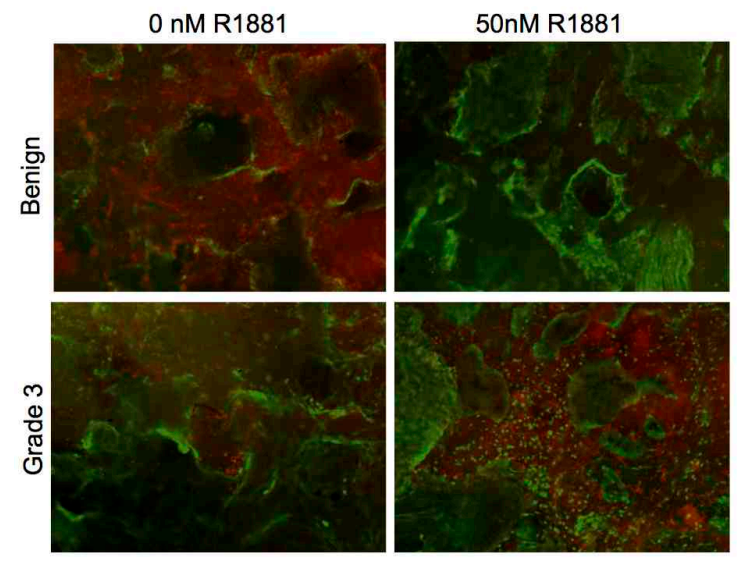

Figure 4. Live/Dead assay on benign and grade 3 PCa TSCs after 5 days in culture ( $4 x$ magnification).
Visualization under a fluorescent microscope revealed primarily red (dead) cells in the benign slices in the absence of R1881 and green (viable) cells in the presence of R1881 (Figure 4). For the reasons described in Aim 1 above, we have not reported these data in a manuscript, but they were in line with the histological and IHC data (Appendix 1, Figure 6). Together, these results show evidence for androgen-dependency of both benign prostate and primary $\mathrm{PCa}$ TSCs, further supporting the biological relevance of the TSC model to the human prostate.

Our third aim is to interrogate applications of the novel in vitro TSC model of

PCa (months 13-24). Although the projected timeline schedules this aim for the forthcoming year, our progress in Aims 1 and 2 have enabled pilot experiments under Aim 3. The tasks under this aim are to (a) evaluate responses to docetaxel and a PI3K inhibitor in PCa TSCs, (b) optimize and characterize the viral tropism of PCa TSCs, and (c) expand the experimental potential and flexibility of the tissue slice graft (TSG) model using TSCs. We have completed an alternative version of task (a) and portions of (b) and (c).

(a) While we proposed to test the effects of the PCa chemotherapeutic docetaxel in the TSCs, docetaxel is reportedly effective in advanced, hormone-refractory PCa (and in combination therapies) (11). Since TSCs model primary PCa, we realized that we might not see any docetaxel-induced effects in our particular model. The natural alkaloid piperlongumine (PL) has garnered recent interest for its cancer-specific anti-proliferative and apoptosis-inducing effects (12). Golovine et al. subsequently tested the effects of PL on PCa cell lines and reported that after only 3 to 6 hours, PL depleted AR and reduced cell proliferation (13). There remains the question of whether the effects of PL on PCa cell lines will be recapitulated in the native prostatic microenvironment and whether PL will affect benign prostate cells as well as the cancer. After confirming the androgen dependence of 
benign and PCa TSCs, we evaluated the effects of PL in this more biologically-relevant system in which we can compare benign and cancer responses within the same specimen.

Six hour treatment with low-dose PL $(10 \mu \mathrm{m})$ appeared to reduce viability and cause epithelial degeneration to a somewhat greater extent in cancer TSCs than in benign as evidenced by MTS assays and H\&E staining, respectively (Appendix 1, Figure 7) (2). We next used IHC to identify cell-specific effects of PL in the benign and cancer TSCs.

Staining for AMACR/p63/CK5 verified the regions of $\mathrm{PCa}$ and benign tissue in the slices. AR expression persisted in benign TSCs after 6 hours of PL treatment, while AR was significantly reduced in PL-treated PCa TSCs. Furthermore, while there was a slight decrease in actively proliferating (Ki67-positive) cells in the PL-treated PCa TSCs, there was a significant increase in PCa cells undergoing apoptosis (Cleaved Caspase 3-positive) compared to benign cells (Appendix 1, Figure 7) (2). Expression of AR, Ki67, and Cleaved Caspase 3 were quantified as described in Aim 2. These results are consistent with and validate the findings by Golovine et al. (although they did not test for apoptosis) while additionally revealing a cancer-specific effect of PL in the prostate that is consistent with findings in other tissue types (12). These results lend support for further investigation into the use of PL in the clinic, and they exemplify the utility of the TSC model for validating preclinical studies previously executed only in cell lines or animal models.

We proposed to evaluate the effects of the PI3K inhibitor LY294002 because Vaira et al. had previously reported on its pharmacodynamics in another version of PCa TSC. However, we were interested in using PL first since it has greater clinical potential than LY294002 for PCa and our model is uniquely poised to evaluate drug specificity. We can follow up this task with investigation of the PL response at the molecular level, performing IHC and qPCR to look into ROS pathway activation and inhibition of STAT3, NFkB, and mTOR signaling (14-17).

(b) We consulted published protocols for viral infection of ex vivo slices of brain and liver tissues to refine our approach to lentiviral infection of prostate TSCs (18-20). We obtained previously-made aliquots of lentivirus containing a GFP construct from our lab

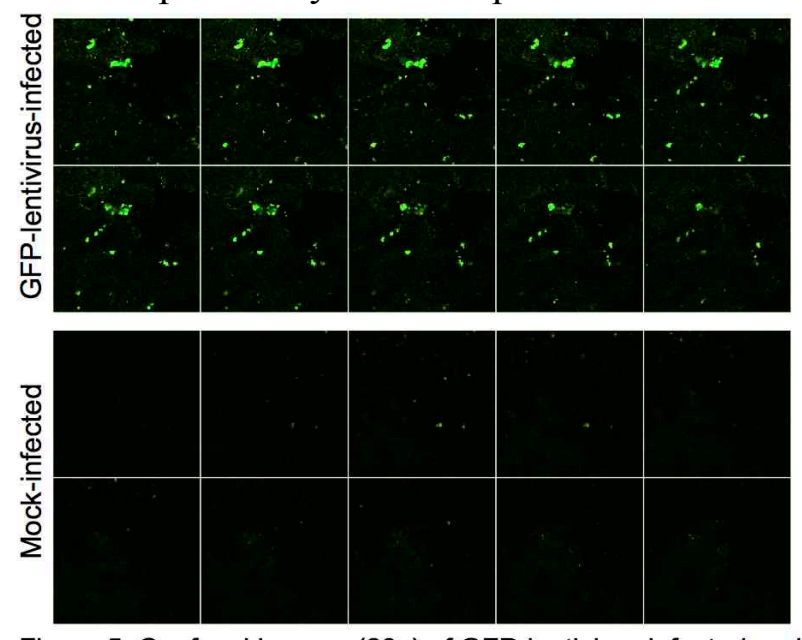

Figure 5. Confocal images (20x) of GFP-lentivirus-infected and mock-infected benign prostate TSCs after 2 days in culture. stores for preliminary experiments on two prostatectomy specimens. We first infected 2 benign slices with 2 different concentrations of GFP-lentivirus, and 2 slices were mock-infected. Polybrene was added to the medium for each slice, and slices were incubated for 24 hours before the viral medium was replaced with fresh medium. Slices were cultured as usual and GFP was visualized by confocal microscopy after 2 and 4 days in culture. Scattered GFP signals were detected to a depth of $\sim 120$ microns 2 days post-infection, but the signal was lost after 4 days (Figure 5).

We tested another infection approach in benign and benign prostatic hyperplasia (BPH) tissue slices. We used a method of pipetting the GFP-lentivirus directly on the top surface of the slice and letting it incubate flat for 2 hours before adding polybrene to the 


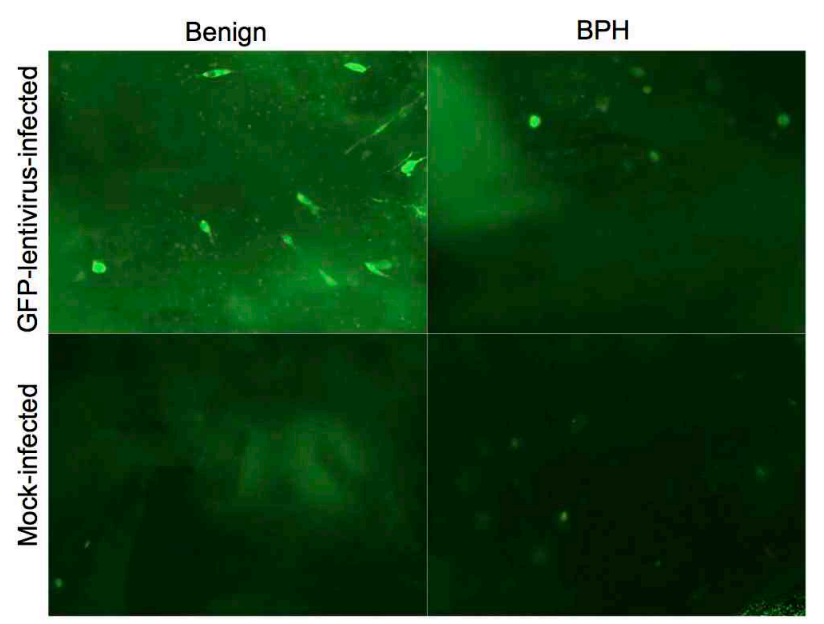

Figure 6. 10x fluorescent images of GFP-lentivirus-infected and mockinfected benign and BPH TSCs 6 hours post-infection. medium and culturing in rotation as usual for a 24 hour infection period. After 24 hours, we replaced the viruscontaining and control media with fresh complete PFMR4A and checked for GFP with a fluorescent microscope 6 hours later. After imaging, we fixed the slices for paraffin embedding and performed IHC for GFP in 5- $\mu$ m sections periodically throughout the slice. This was a mistake, as FFPE is reported to quench the GFP signals. However, we were able to detect GFPpositive cells in the benign slices using whole-mount fluorescence microscopy

(Figure 6). Future work will continue to optimize lentiviral infection of TSCs.

(c) Our lab has previously described a tissue slice graft (TSG) model in which slices of human PCa are embedded under the renal capsules of immune-deficient mice $(21,22)$. The TSG model will benefit from extending the time between sample procurement and engraftment not only by relieving time constraints, but also by allowing experimental manipulation pre-implantation. Our pilot experiments were performed with 2 benign specimens and one PCa specimen. From each case, we generated 16 adjacent slices that were frozen for immediate histological evaluation, processed for FFPE and IHC, cultured for 3 or 4 days as TSCs before implantation or fixation, or immediately implanted under the renal capsules of $\mathrm{RAG} 2^{-/-} \mathrm{YC}^{-/-}$mice ( 3 mice per time point, one slice per mouse) (Figure 7). One $25 \mathrm{mg}$ testosterone pellet was implanted subcutaneously per mouse. After one month, the kidneys were harvested and fixed for histological evaluation of the grafts. Histology of the day 0 grafts was compared to that of tissue slices grafted after 34 days in culture.

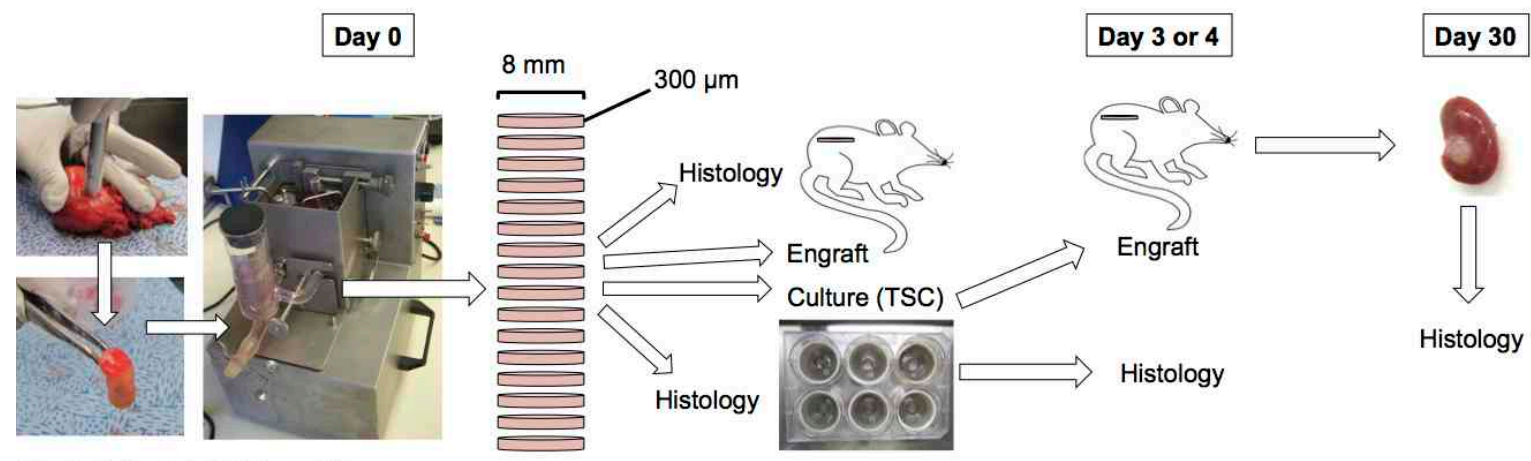

Figure 7. Experimental workflow.

H\&E staining revealed excellent engraftment rates and architectural integrity of benign tissues implanted on both day 0 and day 3 (100\%) (Figure 8). Expression of luminal (AR), basal (CK5, p63), and stromal (SMA) cell markers was maintained in all grafts. Markers for proliferation (Ki67) and physiological function (prostate specific antigen, PSA) were also retained (Figure 8). However, the engraftment and survival of PCa TSCs after 4 days in culture compared to the day 0 grafts was not as successful (Figure 9). Additional PCa specimens must be tested to optimize tumorgraft viability 
after culturing the slices for 3 or 4 days, but our success with implanting benign TSCs is promising. Future work will interrogate the experimental manipulation that may be exacted in vitro pre-implantation, such as infection with a lentiviral luciferase construct for in vivo imaging.
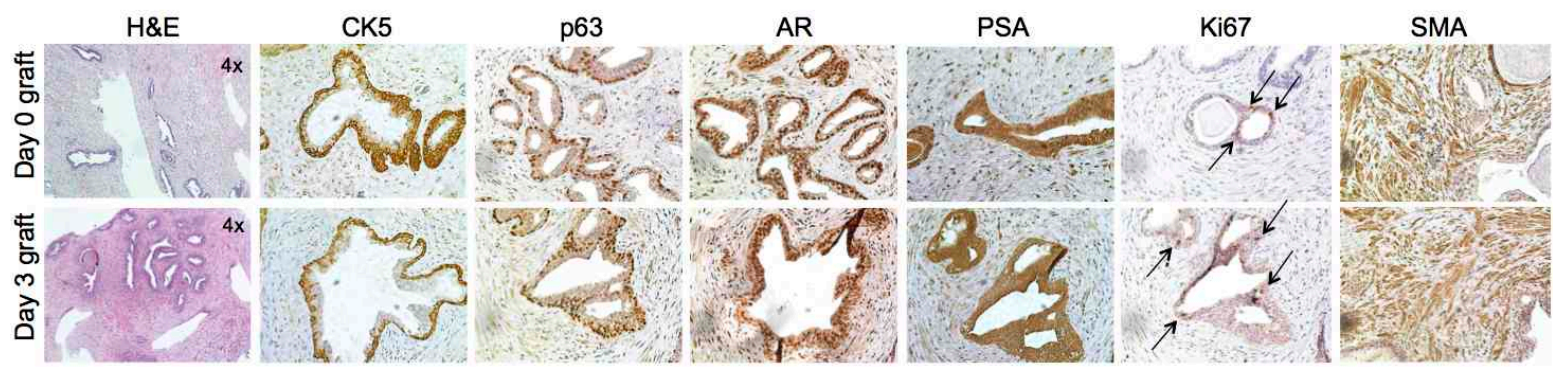

Figure 8. Benign TSCs implanted after 3 days in culture exhibited similar cellular markers and viability as day 0 grafts. After 1 month in vivo, expression of luminal (AR), basal (CK5, p63), and stromal (SMA) cell markers was maintained in grafts implanted on days 0 and 3 ( $n=3$ from 2 specimens each). Markers for proliferation (Ki67, arrows) and physiological function (PSA) were also retained. Representative images are shown at 20x magnification unless otherwise noted.
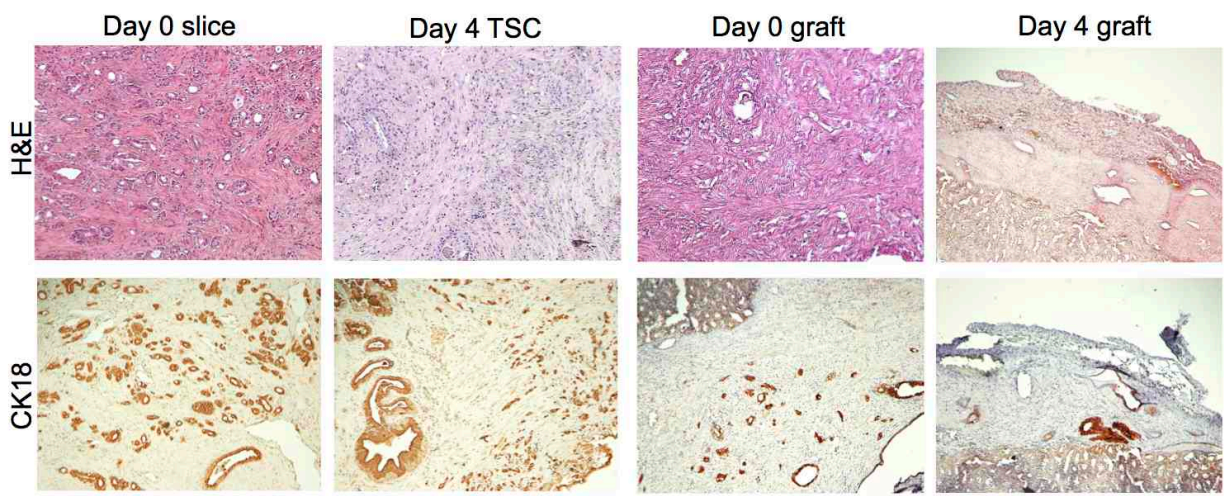

Figure 9. One-month PCa tumorgrafts ( $n=3$ from 1 specimen) were not as well maintained when implanted after 4 days in culture compared to those implanted immediately post-prostatectomy. All images are at $10 x$ magnification.

\section{KEY RESEARCH ACCOMPLISHMENTS}

- Optimized the TSC system for the benign prostate, low-risk, and high-risk PCa, extending viability to 5 days in culture

- Characterized the cellular and molecular heterogeneity in benign and PCa TSCs after 5 days in culture and verified fidelity to the parent tissue

- Characterized the hormone-dependence of benign and PCa TSCs

- Established proof-of-principle for using TSCs to evaluate cancer-specific responses to a pharmacological agent (piperlongumie)

- Combined the TSC model with the in vivo TSG model

\section{CONCLUSION}

We have optimized, characterized, and reported on a novel authentic model for benign and malignant human PCa. Under Aim 1, we met our goals of optimizing PCa TSC of different Gleason grades. While grade $3 \mathrm{PCa}$ is the most common, we also cultured tissue from grade 4 and 5 cases successfully for 5 days in medium with 
optimized concentrations of synthetic androgen R1881. Histological evaluation, IHC for markers of proliferation and apoptosis, and LDH cytotoxicity assays revealed that the cellular architecture remained intact and that the tissue was viable up to 5 days in vitro. Under Aim 2, we validated the TSC system as an authentic model of PCa by verifying the fidelity of cellular composition and biomarker expression in TSCs to the parent tissue. We also validated that TSCs were androgen-dependent and seem to recapitulate in vivo responses to androgen ablation. Under Aim 3, we have begun to interrogate applications of the TSC model by evaluating its response to a pharmacological agent, testing lentiviral infection of TSCs, and combining the TSC model with the in vivo TSG model.

From our work so far, we conclude that the optimized TSC model is a more authentic representation of benign prostate tissue, low-grade, and high-grade primary PCa than current in vitro pre-clinical models. It maintains the native cellular architecture and heterogeneity of the human tissue while exhibiting androgen dependence and functional viability. In addition, it is well suited for pre-clinical studies on drug specificity, and its cancer-specific response to the natural alkaloid piperlongumine supports clinical investigation into this agent. Our collaborators at UCSF have also verified the metabolic viability of prostate TSCs, further supporting its suitability as a preclinical model (23). Finally, we have successfully performed sub-renal implantation of benign TSCs that have been cultured for 3 days, combining the in vitro TSC and in vivo TSG models. Future work will optimize engraftement of PCa TSCs, as well as interrogate the experimental manipulation that may occur pre-implantation. We have begun pilot lentiviral infection experiments, but future work will optimize and characterize the viral tropism of $\mathrm{PCa}$ TSCs.

\section{PUBLICATIONS, ABSTRACTS, AND PRESENTATIONS}

Maund, S.L., Nolley, R., and Peehl, D. (2014) Optimization and comprehensive characterization of a faithful tissue culture model of the normal and malignant human prostate. Laboratory Investigation. 94(2):208-221 (Appendix 1)

The abstract "Combining ex vivo and tumorgraft models of the benign and malignant human prostate" (\#A64) was accepted for poster presentation at the AACR-Prostate Cancer Foundation conference Advances in Prostate Cancer Research, San Diego, CA, January 2014. (Appendix 2)

\section{TRAINING AND PROFESSIONAL DEVELOPMENT}

The Peehl lab and Stanford University both provide supportive training environments and encourage professional development. Dr. Peehl, a veteran mentor, is readily accessible for frequent formal and informal one-on-one discussions. In relation to my research, she works with me to critique my data, view the bigger picture, review experimental designs, and delegate tasks. In addition, she has shown great support for my professional development, encouraging me to acquire teaching experience, attend conferences, and pursue other career-building opportunities. Dr. Peehl directs weekly lab 
meetings in which lab members take turns presenting a journal article or research update, with periodic "Show and Tell" sessions when each member shares recent literature or seminars of interest. We also have sporadic joint lab meetings with Dr. James Brooks' PCa research lab, which help broaden my knowledge base. The consistent lab meetings provide intellectual stimulation, help keep me up-to-date in areas of PCa research, and provide technical support and friendly critique of research directions.

The Department of Urology at Stanford emphasizes close interactions between basic scientists and clinicians to foster translational research, and has several formal activities to bring the two entities together. There is a weekly Urology Research Conference, attended by clinical and research faculty and staff. The Peehl lab typically attends the meetings that focus on PCa or other genitourinary cancers, or those that include basic science research presentations. Attending these meetings brings me in contact with clinicians so that I am comfortable approaching them when I need clinical information. I also attend Tumor Boards on PCa, which is an effective mechanism to help me keep in mind the larger goal of my research: helping patients. Grand Rounds also provide another opportunity to learn about the clinical aspects of PCa. Finally, I present my research annually at a monthly Urology Research Labs Conference attended by the research staff. This conference stimulates interactions with other labs working on PCa. Together, the Department of Urology provides an outstanding training environment because of a strong clinical research program in $\mathrm{PCa}$, emphasis on translational research, and many events that foster interactions between basic scientists and clinicians.

Stanford University and the School of Medicine both have career development offices available to postdoctoral fellows. They run seminars ranging from advice on how to write a research statement and find grant funding to how to use LinkedIn and network. I have also made use of their CV and cover letter review services as well as their libraries of books on career development. Together with the Office of Postdoctoral Affairs, they run the "Academic Chats" seminar series that covers a wide variety of topics related to preparing for, finding, and excelling in academic jobs. I also attend seminars put on by the Lane Medical Library \& Knowledge Management Center on tools and techniques to enhance my research. Finally, other departments at Stanford offer a plethora of seminars and mini-conferences that I attend, such as those sponsored by the Translational Research Program, the Cancer Biology Department, and Bio-X. These provide interaction with Stanford scientists and distinguished guests from outside of the Department of Urology that inspires ideas and interdisciplinary collaboration.

I am involved in several of the Peehl lab's inter-institutional collaborations. Currently, I am working with collaborators at UC Berkeley (Dr. Carolyn Bertozzi) to use metabolic engineering as a platform for proteomic analysis. I am a co-author of one publication that has ensued from this collaboration in the past year, and I will be a coauthor on at least one more (24). This and other multi-disciplinary collaborations provide me with the opportunity to use the optimized TSC model for multiple novel applications, and they provide training in communication and maintaining collaborations. In January of this year, my abstract on the combination of TSC and TSG models was accepted for a poster presentation at the AACR and Prostate Cancer Foundation-sponsored PCa meeting. Attendance at this conference not only exposed me to cutting-edge work in the field, but it also gave me the opportunity to share our model system with potential collaborators and have insightful discussions regarding applications of the model. 
Over the last year and a half I have been developing and teaching my own semester-long course, Cell Biology, at the UC Berkeley Extension one night per week. My multimedia lectures highlight clinical relevance (especially in relation to cancer) and novel research techniques and findings. This experience has not only strengthened my $\mathrm{CV}$, but it has significantly improved my oral communication skills and my ability to explain complex scientific information in a clear and concise manner. I have received consistently excellent evaluations from my students, which has boosted my confidence as both a teacher and a scientist. This year, I had eight weeks of one-on-one coaching to prepare my application materials for the academic job market. Unfortunately, I did not get any interviews. After coming to terms with the level of competition in the San Francisco Bay Area, I expanded my job search to include positions outside of academia in which I could exercise knowledge-based influence on clinical innovation and progress in cancer biology. I attended networking events and conducted several informational interviews with people in industry positions. After much personal reflection, several interviews, and three job offers, I accepted a position in which I will use my research and communication skills honed during my postdoctoral experience to improve the treatment of cancer patients.

\section{OTHER ACHIEVEMENTS}

I was offered a job as a genomic variant curation scientist at SV Biosystems, a company that builds next-generation sequencing-based clinical assays for personalized medicine. I will be analyzing scientific literature on the association of genetic variants with cancer, drug responses, and other disease states and distilling the information into a database that will be accessed for generation of clinical reports for doctors that will help inform patient treatment decisions. SV Biosystems was impressed by my work with the TSC model, since has potential translational applications in personalized medicine.

\section{REFERENCES}

1. K. J. Pienta et al., The current state of preclinical prostate cancer animal models. Prostate 68, 629 (May 1, 2008).

2. S. L. Maund, R. Nolley, D. M. Peehl, Optimization and comprehensive characterization of a faithful tissue culture model of the benign and malignant human prostate. Lab Invest 94, 208 (Feb, 2014).

3. S. A. Bigler, R. E. Deering, M. K. Brawer, Comparison of microscopic vascularity in benign and malignant prostate tissue. Hum Pathol 24, 220 (Feb, 1993).

4. C. De Nunzio et al., The controversial relationship between benign prostatic hyperplasia and prostate cancer: the role of inflammation. European urology $\mathbf{6 0}$, 106 (Jul, 2011).

5. S. A. Tomlins et al., Recurrent fusion of TMPRSS2 and ETS transcription factor genes in prostate cancer. Science 310, 644 (Oct 28, 2005). 
6. A. Chaux et al., Immunohistochemistry for ERG expression as a surrogate for TMPRSS2-ERG fusion detection in prostatic adenocarcinomas. The American journal of surgical pathology 35, 1014 (Jul, 2011).

7. B. Kwabi-Addo et al., Haploinsufficiency of the Pten tumor suppressor gene promotes prostate cancer progression. Proc Natl Acad Sci U S A 98, 11563 (Sep 25, 2001).

8. M. E. McMenamin et al., Loss of PTEN expression in paraffin-embedded primary prostate cancer correlates with high Gleason score and advanced stage. Cancer Res 59, 4291 (Sep 1, 1999).

9. G. L. Wright, Jr., C. Haley, M. L. Beckett, P. F. Schellhammer, Expression of prostate-specific membrane antigen in normal, benign, and malignant prostate tissues. Urol Oncol 1, 18 (Jan-Feb, 1995).

10. M. Jaggi et al., Aberrant expression of E-cadherin and beta-catenin in human prostate cancer. Urol Oncol 23, 402 (Nov-Dec, 2005).

11. D. P. Petrylak, The treatment of hormone-refractory prostate cancer: docetaxel and beyond. Rev Urol 8 Suppl 2, S48 (2006).

12. L. Raj et al., Selective killing of cancer cells by a small molecule targeting the stress response to ROS. Nature 475, 231 (Jul 14, 2011).

13. K. V. Golovine et al., Piperlongumine induces rapid depletion of the androgen receptor in human prostate cancer cells. Prostate 73, 23 (Jan, 2013).

14. D. J. Adams et al., Discovery of Small-Molecule Enhancers of Reactive Oxygen Species That are Nontoxic or Cause Genotype-Selective Cell Death. ACS chemical biology, (Mar 25, 2013).

15. U. Bharadwaj et al., Drug-repositioning screening identified piperlongumine as a direct STAT3 inhibitor with potent activity against breast cancer. Oncogene $\mathbf{0}$, (Mar 31, 2014).

16. S. Ginzburg et al., Piperlongumine inhibits NF-kappaB activity and attenuates aggressive growth characteristics of prostate cancer cells. Prostate 74, 177 (Feb, 2014).

17. P. Makhov et al., Piperlongumine promotes autophagy via inhibition of Akt/mTOR signalling and mediates cancer cell death. Br J Cancer 110, 899 (Feb 18, 2014).

18. T. O. Kirby et al., A novel ex vivo model system for evaluation of conditionally replicative adenoviruses therapeutic efficacy and toxicity. Clin Cancer Res 10, 8697 (Dec 15, 2004).

19. M. G. Rots et al., An ex vivo human model system to evaluate specificity of replicating and non-replicating gene therapy agents. The journal of gene medicine 8, 35 (Jan, 2006).

20. M. U. Ehrengruber et al., Gene transfer into neurons from hippocampal slices: comparison of recombinant Semliki Forest Virus, adenovirus, adeno-associated virus, lentivirus, and measles virus. Mol Cell Neurosci 17, 855 (May, 2001).

21. H. Zhao, R. Nolley, Z. Chen, D. M. Peehl, Tissue slice grafts: an in vivo model of human prostate androgen signaling. Am J Pathol 177, 229 (Jul, 2010).

22. H. Zhao et al., Patient-derived tissue slice grafts accurately depict response of high-risk primary prostate cancer to androgen deprivation therapy. Journal of translational medicine 11, 199 (2013). 
23. K. R. Keshari et al., Metabolic reprogramming and validation of hyperpolarized 13C lactate as a prostate cancer biomarker using a human prostate tissue slice culture bioreactor. Prostate 73, 1171 (Aug, 2013).

24. B. Belardi et al., Imaging the glycosylation state of cell surface glycoproteins by two-photon fluorescence lifetime imaging microscopy. Angew Chem Int Ed Engl 52, 14045 (Dec 23, 2013).

\section{APPENDICES}

Appendix 1 (p. 14). Manuscript reprint and supplemental information: Maund et al. (2014) Optimization and comprehensive characterization of a faithful tissue culture model of the normal and malignant human prostate. Laboratory Investigation. 94(2):208-221

Appendix 2 (p. 35). Abstract reprint: Maund et al. (2014) Combining ex vivo and tumorgraft models of the benign and malignant human prostate (\#A64). AACR-Prostate Cancer Foundation conference Advances in Prostate Cancer Research, San Diego, CA, January 2014

Appendix 3 (p. 36). CV 


\title{
Optimization and comprehensive characterization of a faithful tissue culture model of the benign and malignant human prostate
}

\author{
Sophia Lisette Maund, Rosalie Nolley and Donna Mae Peehl
}

Few preclinical models accurately depict normal human prostate tissue or primary prostate cancer (PCa). In vitro systems typically lack complex cellular interactions among structured prostatic epithelia and a stromal microenvironment, and genetic and molecular fidelity are concerns in both in vitro and in vivo models. 'Tissue slice cultures' (TSCs) provide realistic preclinical models of diverse tissues and organs, but have not been fully developed or widely utilized for prostate studies. Problems encountered include degeneration of differentiated secretory cells, basal cell hyperplasia, and poor survival of PCa. Here, we optimized, characterized, and applied a TSC model of primary human PCa and benign prostate tissue that overcomes many deficiencies of current in vitro models. Tissue cores from fresh prostatectomy specimens were precision-cut at $300 \mu \mathrm{m}$ and incubated in a rotary culture apparatus. The ability of varied culture conditions to faithfully maintain benign and cancer cell and tissue structure and function over time was evaluated by immunohistological and biochemical assays. After optimization of the culture system, molecular and cellular responses to androgen ablation and to piperlongumine (PL), purported to specifically reduce androgen signaling in $\mathrm{PCa}$, were investigated. Optimized culture conditions successfully maintained the structural and functional fidelity of both benign and PCa TSCs for 5 days. TSCs exhibited androgen dependence, appropriately undergoing ductal degeneration, reduced proliferation, and decreased prostate-specific antigen expression upon androgen ablation. Further, TSCs revealed cancer-specific reduction of androgen receptor and increased apoptosis upon treatment with $\mathrm{PL}$, validating data from cell lines. We demonstrate a TSC model that authentically recapitulates the structural, cellular, and genetic characteristics of the benign and malignant human prostate, androgen dependence of the native tissue, and cancer-specific response to a potentially new therapeutic for PCa. The work described herein provides a basis for advancing the experimental utility of the TSC model.

Laboratory Investigation (2014) 94, 208-221; doi:10.1038/labinvest.2013.141; published online 2 December 2013

KEYWORDS: ex vivo; model development; prostate; prostate cancer; tissue slice culture

Prostate cancer $(\mathrm{PCa})$ cell lines and animal models have been extremely valuable in PCa research, but inherent drawbacks hinder their clinical relevance. ${ }^{1,2}$ Cell lines, often artificially immortalized, acquire mutations in culture and lack the cellular interactions with a prostate microenvironment that are critical for prostate function and tumorigenesis. ${ }^{3}$ Animal models may not physiologically or genetically represent true human prostate pathology. ${ }^{1,2,4}$ There are currently few models of primary $\mathrm{PCa}$, which historically has been difficult to maintain in culture or in vivo. ${ }^{5}$

To address these limitations, we and others have developed an ex vivo 'tissue slice culture' (TSC) model of the benign and malignant human prostate. TSC purports to be an authentic model because it preserves native tissue architecture and functional differentiation, maintaining cellular heterogeneity and complex cell-cell interactions within the intact microenvironment. TSC has been a useful practice with other organs, ${ }^{6-8}$ and the advantages of TSC compared with monolayer cell culture are illustrated in many studies. ${ }^{9-11}$ Of note, the intact tumor microenvironment allows stromalepithelial interactions that are critical for realistic studies of tumor metabolism. ${ }^{12,13}$ With collaborators, we found that TSCs exhibit steady-state glycolytic and phospholipid metabolism that mirrors that of human PCa in vivo but is not exhibited in PCa cell lines. ${ }^{14}$ Such deviations from human physiology often result in inaccurate preclinical

Department of Urology, Stanford University School of Medicine, Stanford, CA, USA

Correspondence: Dr DM Peehl, PhD, Department of Urology, Stanford Medical Center, Stanford, CA 94305-5118, USA.

E-mail: dpeehl@stanford.edu

Received 8 May 2013; revised 4 October 2013; accepted 28 October 2013 

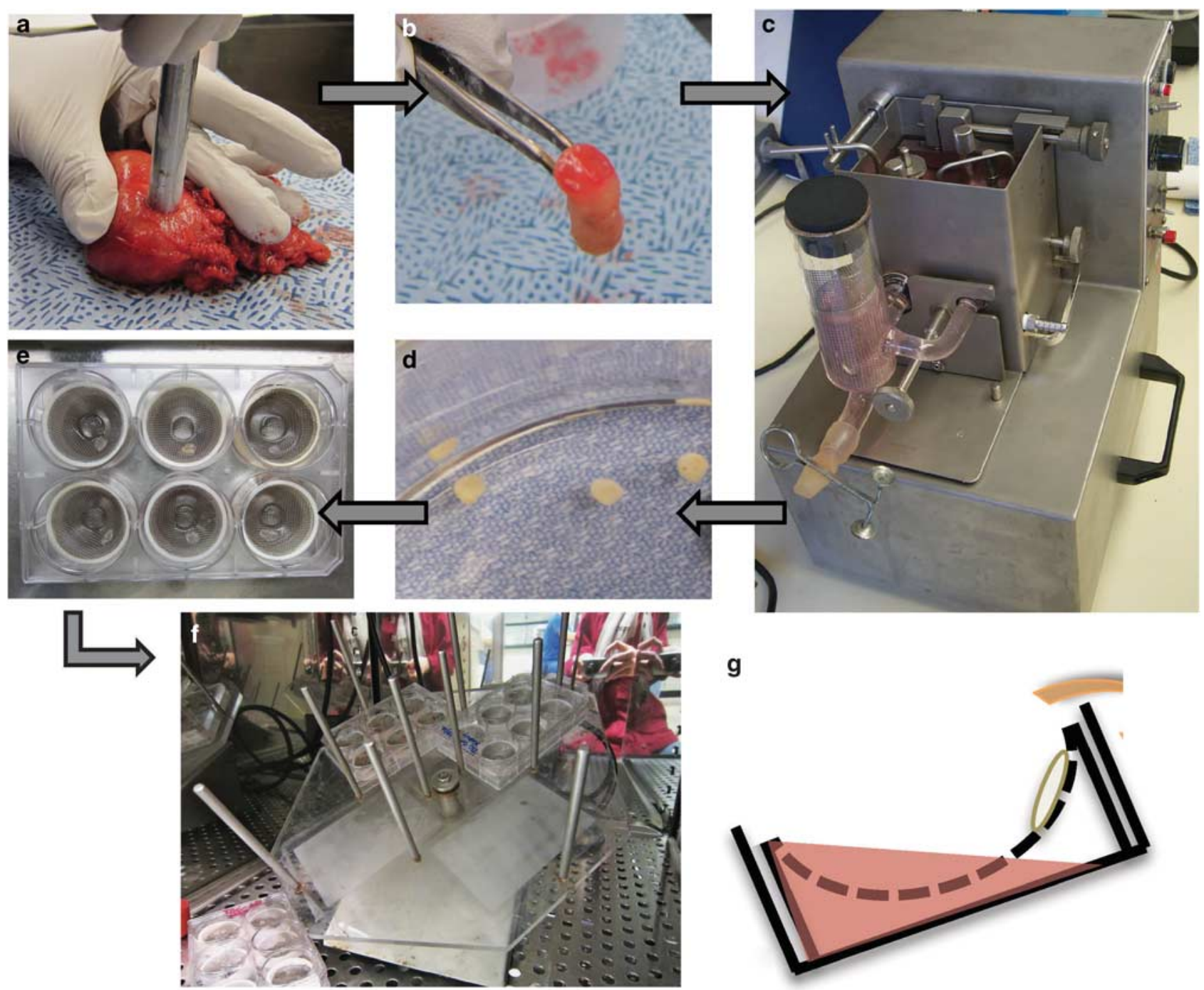

Figure 1 Schematic for tissue slice acquisition and culture. Cores 8-mm in diameter were taken from radical prostatectomy specimens (a, b) and placed in the Krumdieck tissue slicer (c) from which slices emerged in a sequential manner (d). Slices were placed on titanium mesh inserts in six-well plates with $2.5 \mathrm{ml}$ culture medium (e). Plates were mounted on an angled rotating platform in a tissue culture incubator (f). The angled rotation caused intermittent submersion of the tissue slices, facilitating diffusion of gas and nutrients from all sides of the slices $(\mathbf{g})$.

assessment of drug responses in cell lines or animal models, leading to wasted efforts on clinical trials with drugs that are unlikely to work. TSCs, however, show promise in betterpredicting drug responses in humans. ${ }^{13,15}$

Ex vivo culture of the human prostate has been problematic, with benign tissues often exhibiting degradation of luminal epithelial cells and hyperproliferation of basal cells. ${ }^{16-18}$ Maintenance of PCa tissue in vitro has presented even more challenges than benign tissue. ${ }^{16,19}$ Relatively recent technological innovations, particularly the practice of precision-cut slicing, ${ }^{6}$ have led to the current form of the prostate TSC model in which $250-500 \mu \mathrm{m}$ thick slices of tissue, $5-8 \mathrm{~mm}$ in diameter, are cultured under defined conditions. ${ }^{18-23}$ Precision-cutting reduces sources of error due to variations in slice thickness and damage to cut surfaces, which both contribute to uneven gas and nutrient exchange throughout tissue slices. It enhances reproducibility when working with heterogeneous tissues such as prostate, allowing adjacent slices to be evaluated for histology and compared pairwise under different experimental conditions. In addition, benign and PCa tissues may be compared from the same specimen. Variations of prostate TSC have been reported with mixed results. ${ }^{18,19}$ With collaborators, we were the first to report the experimental implementation of a normal prostate TSC model, identifying altered DNA damage response mechanisms by which prostatic epithelia may be predisposed to malignant transformation. . $1,22,24^{2}$

Although these studies underscore the novel experimental potential of prostate TSCs, the model remains underutilized. This is in large part because of the need for further optimization and thorough characterization of the model as well as for additional feasibility studies to encourage its use. The 
Table 1 Antibody information

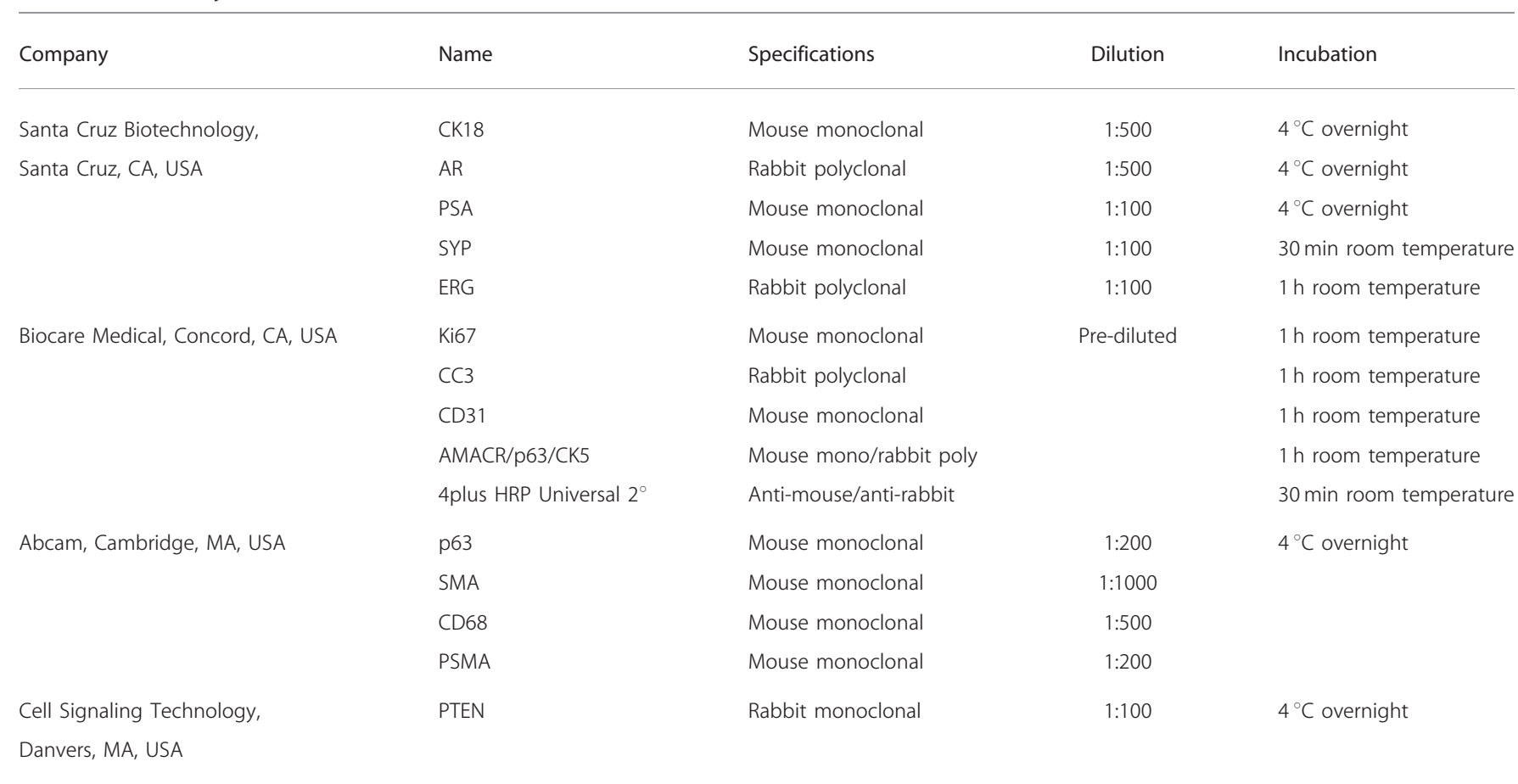

ability to culture primary PCa is a unique feature of TSC that will confer greater authenticity to preclinical studies. One of the few reports involving PCa TSC was a pharmacodynamic profiling study reporting that TSCs were reproducible and accurate models for preclinical evaluation of drug responses. ${ }^{15}$ As evidenced in other TSC systems, extending viability in culture beyond 2-3 days allows modeling of chronic as well as acute toxicity studies, including the metabolic activity of the tissue. ${ }^{25-27}$

Our objectives were to systematically optimize and comprehensively characterize both benign and PCa TSCs in order to potentiate the utility of the model. Modifications of the culture system permitted maintenance of benign differentiated secretory epithelia in the absence of basal cell hyperplasia for up to 5 days. Primary PCa of Gleason grades 3, 4, and 5 also remained viable under optimized conditions. We showed that TSCs are androgen responsive and maintained the microenvironment and heterogeneity of the native tissue, qualities that support their use as an authentic preclinical model for PCa. Finally, we used TSCs to test the cancerspecific effects of the natural compound piperlongumine (PL), which was recently evaluated in PCa cell lines. ${ }^{28}$

\section{MATERIALS AND METHODS}

\section{Culture of Prostate Tissue Slices}

Information about donors and tissues is presented in Supplementary Table 1. Figure 1 illustrates the acquisition, generation, and culture of prostate TSCs. Radical prostatectomy specimens were obtained immediately post surgery and $8-\mathrm{mm}$ diameter cores of putative benign and PCa regions were taken from the peripheral zones according to needle biopsy maps and gross analysis (Figure 1a and b). The cores were aseptically precision-cut to $300-\mu \mathrm{m}$ thickness in the Krumdieck Tissue Slicer (Alabama Research and Development, Mundford, AL, USA) ${ }^{8,29}$ from which they emerged in a sequential manner (Figure $1 \mathrm{c}$ and $\mathrm{d}$ ). Alternating slices were formalin-fixed for paraffin-embedding or frozen and sectioned for histological verification by hematoxylin and eosin (H\&E) staining (Supplementary Figure 1). Adjacent slices were transferred with sterile forceps onto titanium mesh inserts in six-well plates with $2.5 \mathrm{ml}$ of culture medium and one to five tissue slices per well (Figure 1e). The plates were incubated at $37^{\circ} \mathrm{C}$ with $95 \%$ air $/ 5 \% \quad \mathrm{CO}_{2}$ on a rotating platform set at a $30^{\circ}$ angle (Alabama Research and Development, Figure 1f). Intermittent submersion in the medium caused by the angled rotation facilitates nutrient and gas diffusion throughout the $300-\mu \mathrm{m}$ slices (Figure 1g), which is critical for maintaining cell viability over time. M199, keratinocyte serum-free medium (KSFM), and antibiotic/antimycotic were from Gibco Life Technologies (Grand Island, NY, USA) and were prepared as in Blauer et al. ${ }^{19}$ Complete PFMR-4A was prepared as previously reported..$^{30}$ Dihydrotestosterone (DHT; Steraloids, Newport, RI, USA) and R1881 (Perkin Elmer, Waltham, MA, USA) stocks were prepared in ethanol (Sigma-Aldrich, St Louis, MO, USA). Piperlongumine (Indofine Chemical Company, Hillsborough, NJ, USA) was prepared in dimethyl sulfoxide (Fisher Scientific, Hampton, NH, USA).

\section{Tissue Histology and Immunohistochemistry}

Tissue slices were fixed in 10\% buffered formalin overnight at room temperature. The slices were then either embedded in 
OCT compound and frozen at $-80^{\circ} \mathrm{C}$ or dehydrated and embedded in paraffin according to standard practices. Serial $5-\mu \mathrm{m}$ slices were cut for histological and immunohistochemical procedures. Formalin-fixed, paraffinembedded sections were deparaffinized, rehydrated, and prepared for immunohistochemistry (IHC) as described previously. ${ }^{31}$ The $5-\mu \mathrm{m}$ sections were incubated with primary and secondary antibodies listed in Table 1 and labeled with alkaline phosphatase (Biocare Medical, Concord, CA, USA), Warp Red Chromogen (Biocare Medical), and/or 3,3-diaminobenzidine (Dako, Carpinteria, CA, USA) according to specifications and counterstained with hematoxylin. Immunohistochemical quantification was performed by blindly counting total cells and IHC-positive cells from three to six random $\times 40$ fields from each of three tissue slices per experimental condition. The percent IHC-positive cells per field was calculated and presented as the mean \pm s.d. Statistical significance was determined by paired Student's $t$-tests.

\section{Lactate Dehydrogenase and MTS Assays}

Conditioned media were collected, spun down, and stored at $-80{ }^{\circ} \mathrm{C}$. The Cytotoxicity Detection Kit Plus (lactate dehydrogenase; LDH) (Roche, Indianapolis, IN, USA) was used to measure $\mathrm{LDH}$ activity in conditioned media as directed. The CellTiter 96 Aqueous One Solution Cell Proliferation Assay (Promega, Madison, WI, USA) was used to measure tissue slice viability. Slices were incubated in culture medium containing the MTS reagent for $2.5 \mathrm{~h}$ at $37^{\circ} \mathrm{C}$ and absorbances were measured as directed. LDH and MTS activity readouts were normalized to the weights in $\mathrm{mg}$ of the corresponding tissue slices and presented as means \pm s.d. $(n=3)$. Statistical significance was determined by paired Student's $t$-tests.

\section{RESULTS}

\section{Optimization of TSC Conditions}

The lab previously developed a serum-free medium, 'Complete PFMR-4 A,' for primary culture of human prostatic cells. ${ }^{30}$ This medium, with the addition of $10 \mathrm{nM}$ of the synthetic androgen R1881, kept benign prostate TSCs viable for $\sim 2$ days before luminal degeneration occurred. We used these conditions as a starting point to further optimize prostate TSC to extend viability and maintain authentic prostate structure and function in vitro for up to 5 days.

Complete PFMR-4A medium with $10 \mathrm{nM}$ R1881 was compared with a medium composed of KSFM/M199 with $1 \mathrm{nM}$ DHT; this medium was previously reported to maintain normal prostate TSCs up to 7 days. ${ }^{19}$ The media were changed every other day and TSCs from multiple prostate specimens were evaluated (Supplementary Tables 1 and 2). In our hands, the KSFM/M199-based medium caused basal cell hyperplasia and occasional luminal degeneration after 5 days of culture, whereas TSCs in Complete PFMR-4A with $10 \mathrm{nM}$ R1881 exhibited luminal degeneration as previously observed as well as occasional basal cell hyperplasia (Figure 2a and Supplementary Tables 1 and 2). IHC for markers of basal cells (p63) and actively proliferating cells (Ki67) confirmed basal cell hyperplasia in the tissues cultured in the KSFM/M199based medium (Figure 2a). Representative negative controls for IHC are included in Supplementary Figure 2. Antioxidants $\mathrm{N}$-acetyl cysteine and L-arginine have each been reported to aid survival in organotypic and cell cultures. ${ }^{32-34}$ Each was added to the Complete PFMR-4A medium and tissue slices were evaluated histologically over time, but neither compound prevented luminal epithelial degeneration (data not shown).

Increasing the concentration of R1881 in Complete PFMR$4 \mathrm{~A}$ revealed that $50 \mathrm{nM}$ prevented luminal epithelial degeneration up to 5 days in culture (Figure 2a, Supplementary Figure 3; Supplementary Tables 1 and 2). A single layer of p63-positive basal cells topped by secretory luminal cells, with one to two Ki67-positive cells per gland, accurately reflected native ('day 0') tissue histology and phenotype (Figure 2a). Although we have not yet extensively characterized TSCs beyond 5 days, preliminary studies indicate that basal cell hyperproliferation and overall degeneration of both benign and PCa tissues become apparent after 1 week.

It has long been understood that tissue viability is enhanced when the culture medium is periodically refreshed to maintain sufficient levels of supplements and to remove metabolic waste products that can be damaging when present in the cellular environment. ${ }^{35,36}$ This is particularly important for metabolic studies, and perfusion culture systems in bioreactors have been shown to enhance survival and realistically maintain cellular metabolism. ${ }^{14,36,37}$ For our purposes, changing the culture medium every day appeared to enhance prostate TSC survival over changing the culture medium every other day. There was no perceived benefit to changing the medium more than once per day (data not shown).

\section{TSC of Primary PCa of Different Gleason Grades}

After extending the maintenance of benign prostate TSCs with the optimized PFMR-4A-based medium, we tested the efficacy of these conditions with PCa TSC of different Gleason grades. Using medium supplemented with $50 \mathrm{nM}$ R1881 and changing media daily successfully maintained the native histology of Gleason grade 3 (low grade), 4, and 5 (high grade) PCa tissue slices up to 5 days in culture (Figure 2b; Supplementary Table 1). We used a triple IHC stain to verify the cancerous regions: the presence of cytoplasmic $\alpha$-methylacyl coenzyme A racemase (AMACR) staining and coincident absence of both nuclear p63 and cytoplasmic cytokeratin 5 (CK5) staining indicate malignancy, whereas the presence of nuclear p63 and cytoplasmic CK5 staining in basal cells in the absence of cytoplasmic AMACR indicate normal tissue. ${ }^{38}$ Benign glands can be interspersed in regions of cancer, as indicated by the arrows in Figure $2 b$. 
a

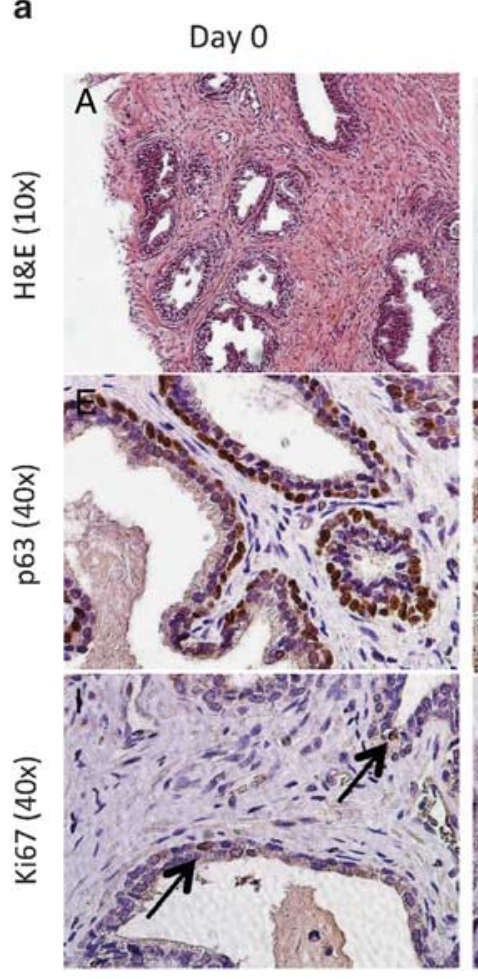

PFMR-4A + 50nM

R1881, Day 5*
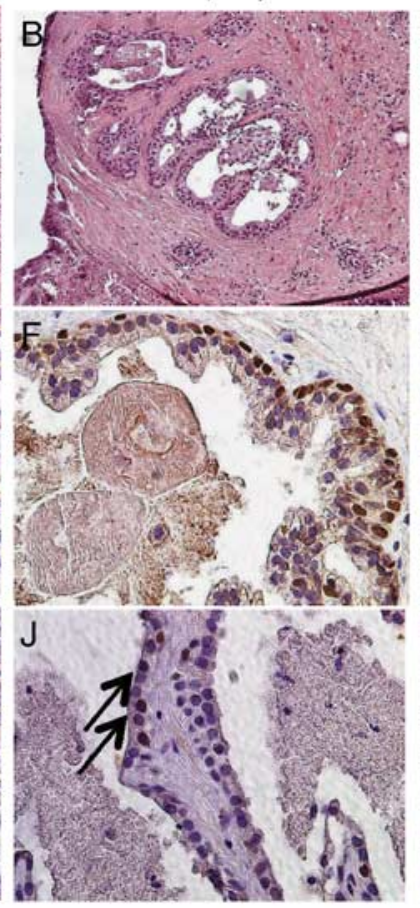

b
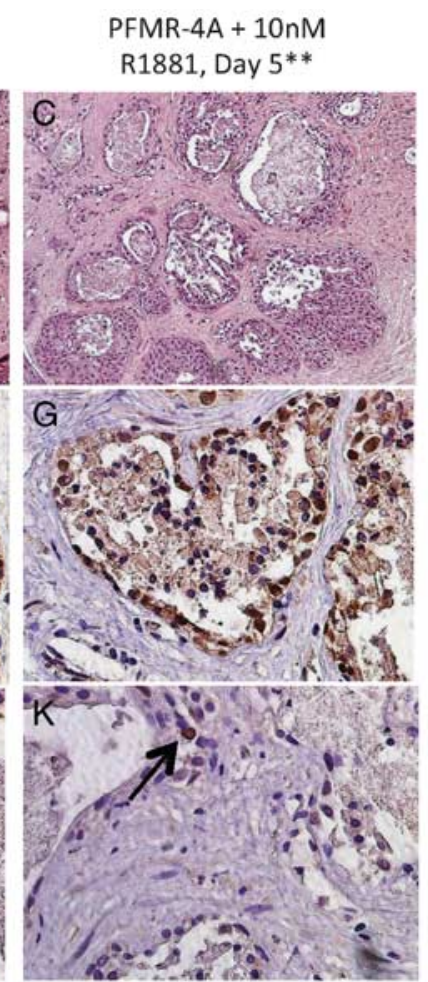

KSFM/M199 + 1nM

$\mathrm{DHT}$, Day $5^{* *}$
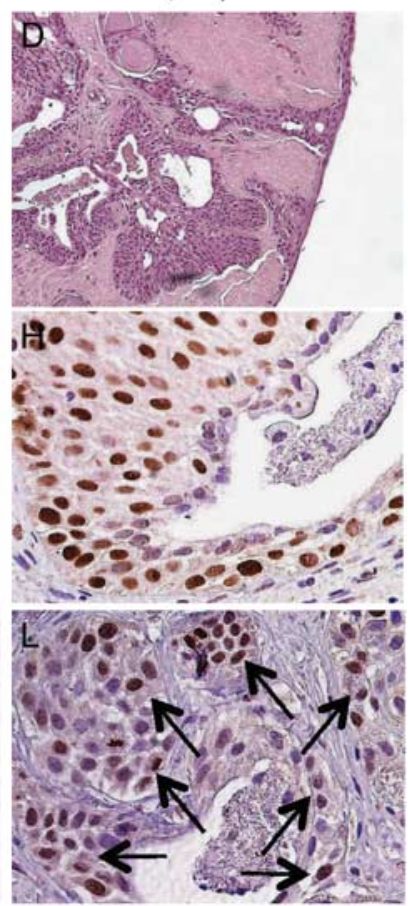
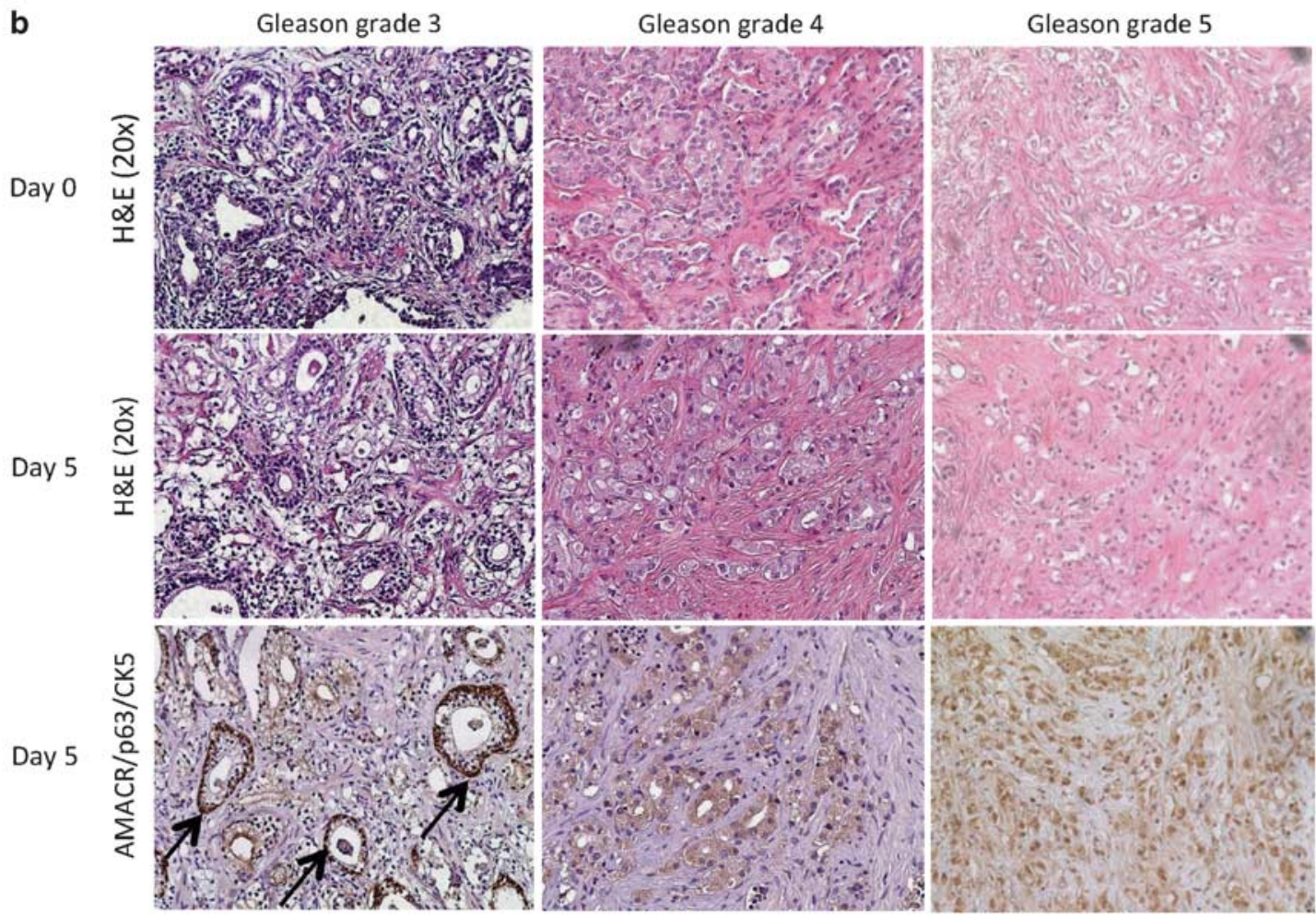

Figure 2 Histology of benign and prostate cancer (PCa) tissue slice cultures (TSCs). (a) Hematoxylin and eosin (H\&E; a-d) and immunohistochemistry (IHC) for p63 (e-h) and Ki67 (i-l, arrows indicate positive nuclei) showed benign TSCs undergoing luminal cell degeneration and/or basal cell hyperproliferation compared with the native tissue ('day 0') when cultured in PFMR-4A with $10 \mathrm{nM} \mathrm{R} 1881$ (c, $\mathbf{g}, \mathbf{k}$ ) or keratinocyte serum-free medium (KSFM)/M199 with $1 \mathrm{nM}$ dihydrotestosterone (DHT; d, h, I), but not in PFMR-4A with $50 \mathrm{nM} \mathrm{R} 1881$ (b, f, j) for 5 days. *Medium changed every $24 \mathrm{~h}$. ** Medium changed every $48 \mathrm{~h}$. (b) Gleason grades 3, 4, and 5 PCa TSCs cultured in PFMR-4A medium with $50 \mathrm{nM}$ R1881 for 5 days exhibited histologic fidelity to the native 'day 0 ' tissue as evidenced by H\&E staining. $\alpha$-Methylacyl coenzyme A racemase (AMACR)/p63/cytokeratin 5 (CK5) staining revealed regions of cancer and some interspersed benign glands (arrows). Representative images were from patient specimens number 12 (a), 18, 27 , and 30 (b, Supplementary Table S1). 


\section{Optimized Culture Conditions Maintain Viability of Benign and PCa TSCs}

Quantitative assays were performed to evaluate overall cell viability and cytotoxicity in TSCs in different culture conditions. MTS assays, which are biochemical measures of viability, revealed a significant improvement in the survival of benign TSCs under the optimized culture condition at day 5 compared with the other conditions tested (Figure 3a). LDH assays, which measure cytotoxicity, showed decreased cytotoxicity under optimized conditions (Figure 3b). PCa TSC viability and cytotoxicity levels were on par with those of the benign prostate TSCs in the optimized medium (Figure 3a and $\mathrm{b}$ ). MTS and LDH assay results corresponded to the qualitative histological assessments represented in Figure 2. Further, cleaved caspase 3 (CC3), a marker of apoptosis, was not detected in TSCs cultured for 5 days in the optimized culture system (Figure 3c and d). Ki67, a marker for proliferating cells, was present in $\sim 2 \%$ of benign epithelial cells and $\sim 7 \%$ of cancer cells in both native tissue and day 5 TSCs (Figure 3d). The percentages of CC3- and Ki67-positive nuclei were quantified from three random $\times 40$ fields from each of three tissue slices per condition (average of 97 nuclei per field), and there were no statistically significant differences between days 0 and 5 (Figure 3d). Importantly, prostate-specific antigen (PSA) continued to be expressed in the benign luminal epithelial cells and cancer cells in TSCs at 5 days, suggesting sustained prostatic function in vitro (Figure 3c). Together, these histological, biochemical, and immunohistochemical assays confirm the functional viability of both benign and PCa TSCs up to 5 days in culture.

\section{Benign and PCa TSCs Maintain the Cellular Complexity of the Native Tissue}

One of the major advantages of the TSC model over current in vitro models is its potential to preserve the structural and cellular diversity of the human prostate. Cellular and molecular heterogeneity and dependence on endocrine and paracrine signaling are important elements of human PCa that are lacking in current in vitro models. Cross talk between the epithelia and the stromal microenvironment, which includes fibroblasts, vasculature, nerves, and cells of the immune system, is critical to functions of the normal prostate as well as to cancer progression. ${ }^{3,39,40}$ Benign and cancer tissues were obtained from the same specimen and IHC was performed for lineage-specific markers of the various cell types within the human prostate at day 0 (immediately post surgery) and in adjacent TSCs after 5 days (Figure 4). The basal epithelial cell marker (p63) was present in a single layer in benign glands but was absent from malignant glands as expected, whereas cytokeratin 18 (CK18) was present in both benign luminal epithelia and cancer, as appropriate. Smooth muscle $\alpha$-actin (SMA) was present throughout the stroma as expected in both benign and cancer tissues. CD31 staining of endothelial cells showed evidence of vasculature in the stroma, more so in regions of cancer as has been previously observed. ${ }^{41}$ CD68 is a cell surface glycoprotein expressed by macrophages and monocytes, and its increased presence in cancer compared with benign tissue reflects an inflammatory phenotype common to $\mathrm{PCa}^{40}$ Finally, a marker for neuroendocrine cells, synaptophysin, was expressed in distinct cells within the basal cell layer in the benign tissue and in sporadic cancer cells as expected (Figure 4). ${ }^{42}$ Overall, these results demonstrate that benign and cancer tissue slices cultured for 5 days in our system retain much of the cellular complexity of native tissues, validating the fidelity of the TSC model of the human prostate.

\section{Benign and PCa TSCs Retain Biomarker Expression Patterns of Native Tissue}

After confirming that prostate TSCs maintained the cellular composition of the native tissue, we next investigated maintenance of expression of biomarkers that are differentially expressed in PCa by IHC in tissue slices cultured for 5 days (Figure 5). AMACR/p63/CK5 triple staining, used to confirm the presence of $\mathrm{PCa}$ in clinical specimens, distinguished regions of benign and malignant tissue in TSCs. The TMPRSS2-ERG gene fusion, occurring in $\sim 40 \%$ of prostate tumors, leads to androgen-driven upregulation of the ERG transcription factor. ${ }^{43}$ Using ERG expression as a surrogate marker for the TMPRSS2-ERG fusion, ${ }^{44}$ we identified PCa specimens that expressed ERG but observed that ERG expression was reduced in the TSCs after 5 days in culture. Although it is possible that androgen signaling is less robust in TSCs, TMPRSS2 expression was well-maintained at day 5. Androgen receptor (AR) expression was detected in both benign and PCa-native tissues and in TSCs after 5 days in culture. PTEN was identified in both benign and PCa specimens but to a somewhat lesser extent in $\mathrm{PCa}$, which may be due to haploinsufficiency. ${ }^{45,46}$ Both benign and PCa TSCs maintained the PTEN expression of the native tissues after 5 days in culture. Prostate-specific membrane antigen (PSMA) was detected in benign and malignant glands as expected in both native tissue and in TSCs after 5 days. ${ }^{47}$ In both native tissue and the day-5 TSCs, E-cadherin was expressed at the cell membrane of benign epithelial cells but exhibited more diffuse cytoplasmic staining in the PCa cells as expected. ${ }^{48}$ Overall, the fidelity of protein expression patterns in TSCs to the native tissues together with their cellular and structural fidelities show that the TSC model uniquely recapitulates prostate biology on structural, cellular, and molecular levels.

\section{Benign and PCa TSCs Exhibit Androgen Dependence}

Benign human prostate and PCa are both highly dependent on androgen signaling, and we showed in Figure 5 that both benign and PCa TSCs express AR. In order to further evaluate the authenticity of the TSC model, the response of TSCs to androgen ablation was assessed. Benign and PCa TSCs were cultured in Complete PFMR-4A medium in the presence (50 $\mathrm{nM} \mathrm{R} 1881)$ or absence (0.05\% ethanol control) 
a

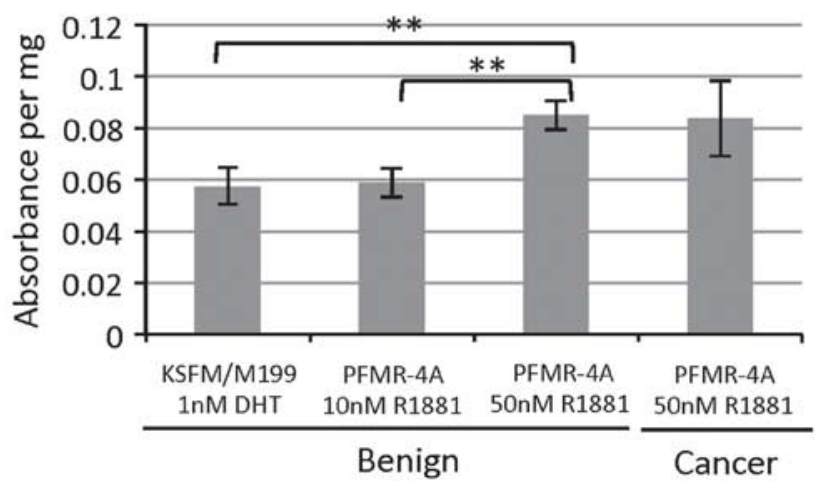

C

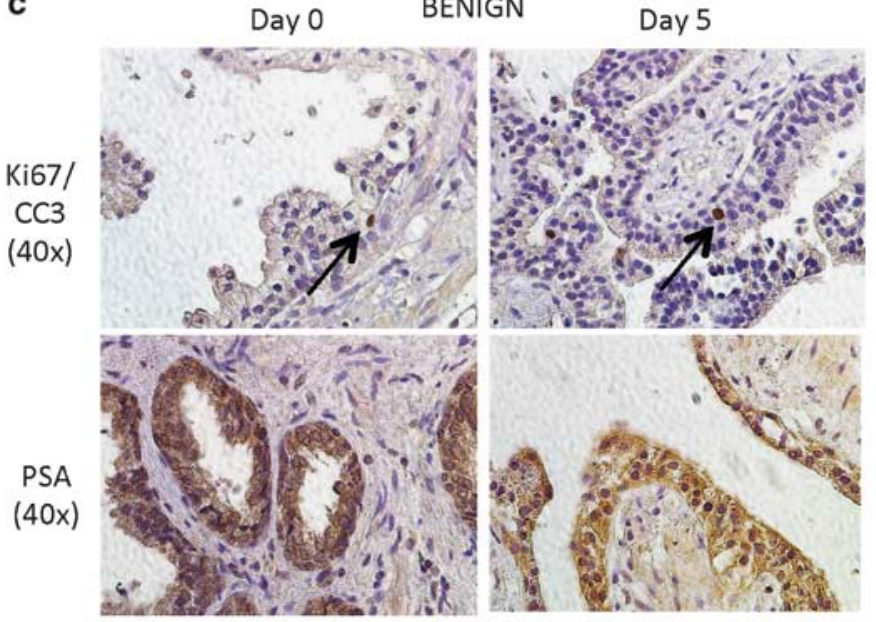

b

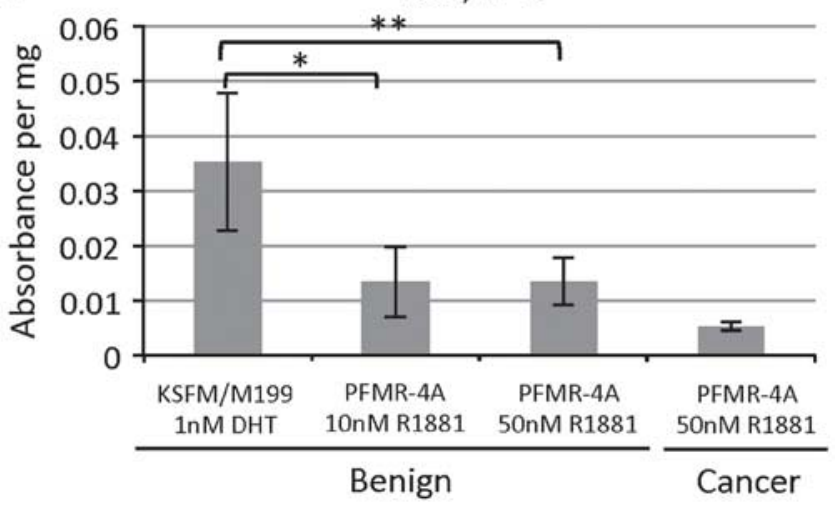

$\mathrm{LDH}, \mathrm{n}=3$

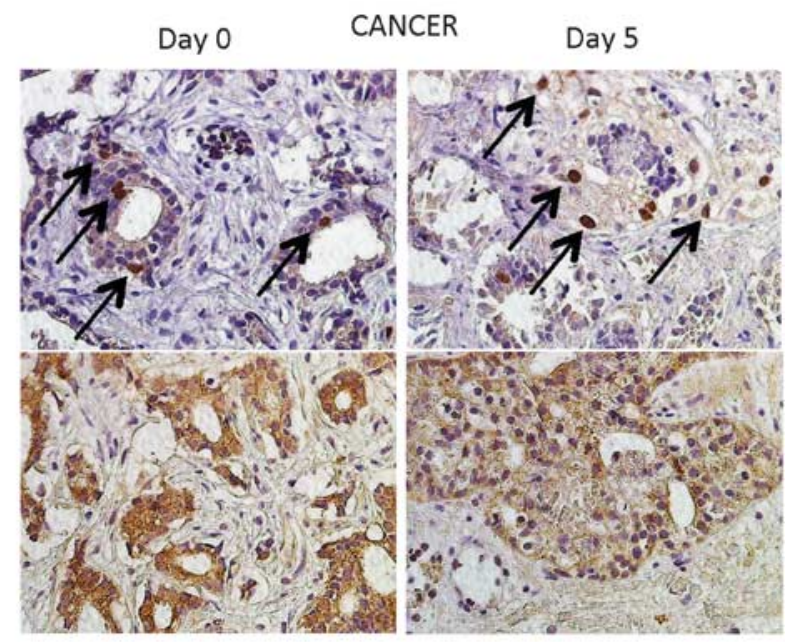

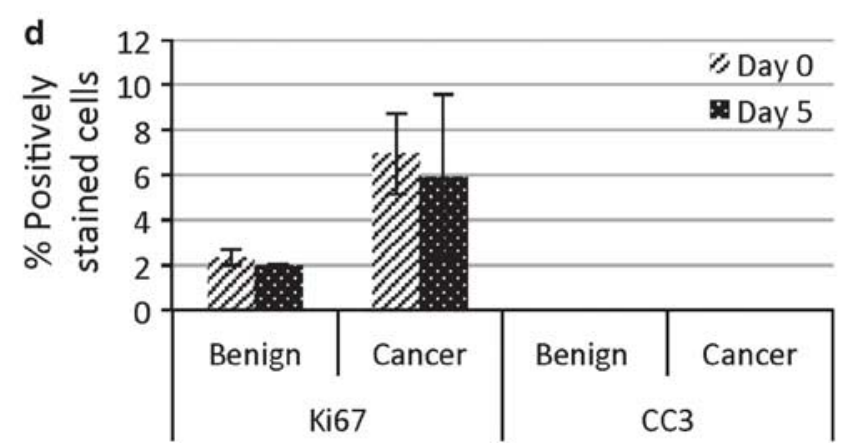

Figure 3 Tissue slice culture (TSC) viability and cellular activity. Benign TSCs cultured in PFMR-4A with 50 nM R1881 for 5 days exhibited increased viability by MTS assay (a) and reduced cytotoxicity by lactate dehydrogenase (LDH) assay (b) compared with those cultured under different conditions. Prostate cancer (PCa) TSCs exhibited levels of viability (a) and cytotoxicity (b) similar to those of benign TSCs. ${ }^{*} P<0.01$, ${ }^{* * P}<0.001$. (c) Benign and PCa TSCs cultured for 5 days in PFMR-4 A with $50 \mathrm{nM}$ R1881 maintained the same proliferative and apoptotic profiles as the native tissue ('day 0') as evidenced by the presence of Ki67-positive cells (arrows) and the absence of cleaved caspase 3 (CC3) staining, respectively (top row, quantified in d). They also continued to express prostate-specific antigen (PSA; bottom row). (d) The percentages of CC3- and Ki67-positive nuclei were quantified from three random $\times 40$ fields from each of three tissue slices per condition (average of 97 nuclei per field). Experiments were performed on patient specimens number 19, 20, 21 (a, b), 14, and 18 (c).

of androgen. Upon histological evaluation after 5 days in culture, there was evidence of ductal degeneration in regions of both benign and cancer TSCs in the absence of androgen (Figure 6b, arrows, Supplementary Tables 1 and 2). An MTS assay showed a statistically significant reduction of viability in benign TSCs but not cancer after 5 days in the absence of androgen (Figure 6a). However, there is likely a hetero- geneous response to androgen ablation among the cell types in both benign and cancer TSCs, as the histology suggested, which may not be revealed by the MTS assay.

We used IHC to further investigate the effects of androgen ablation on TSCs. After 5 days, evidence of proliferating cells (Ki67-positive, black arrows) decreased and evidence of apoptotic cells (CC3-positive, red arrows) increased in both 
BENIGN

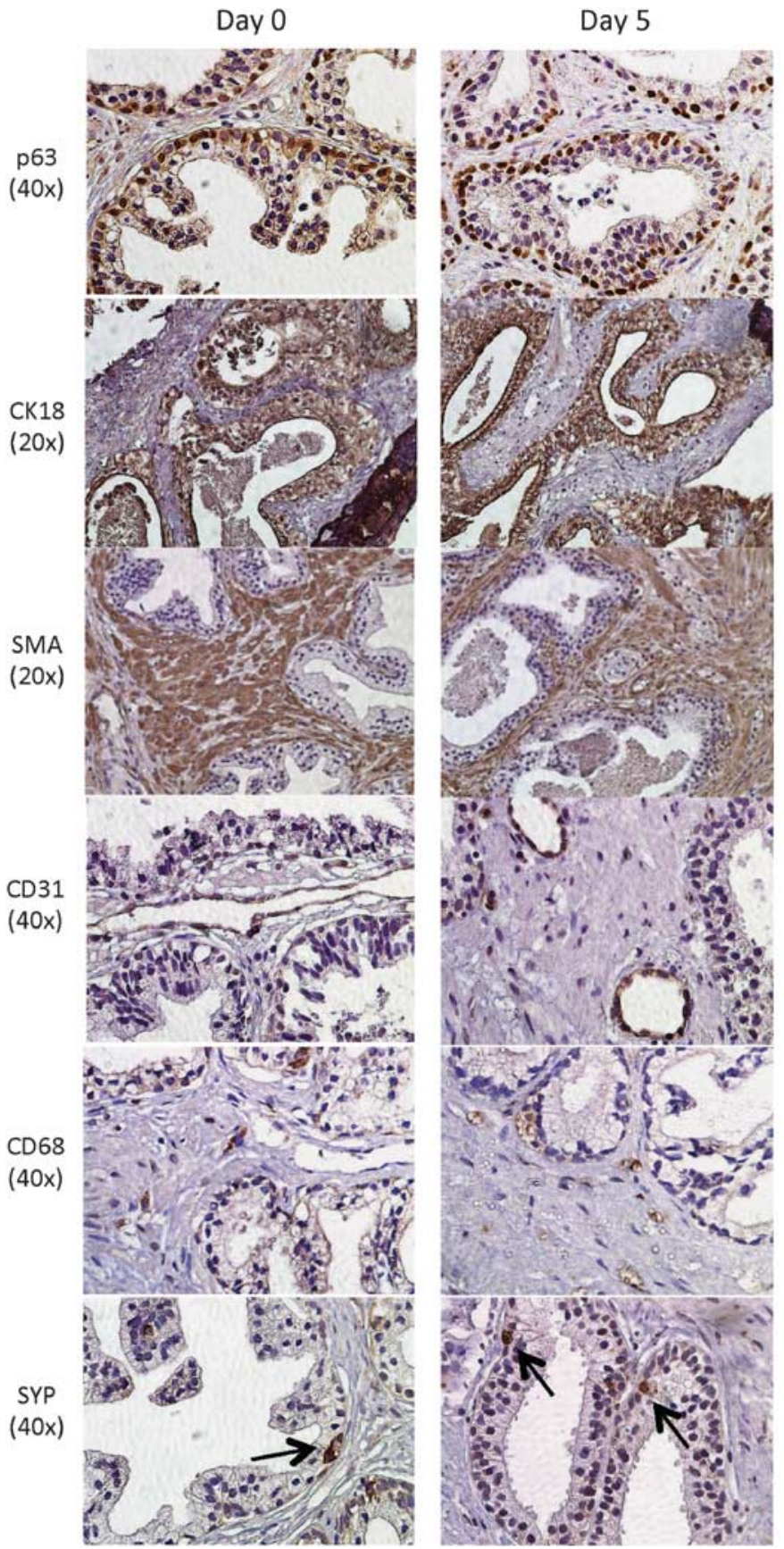

CANCER

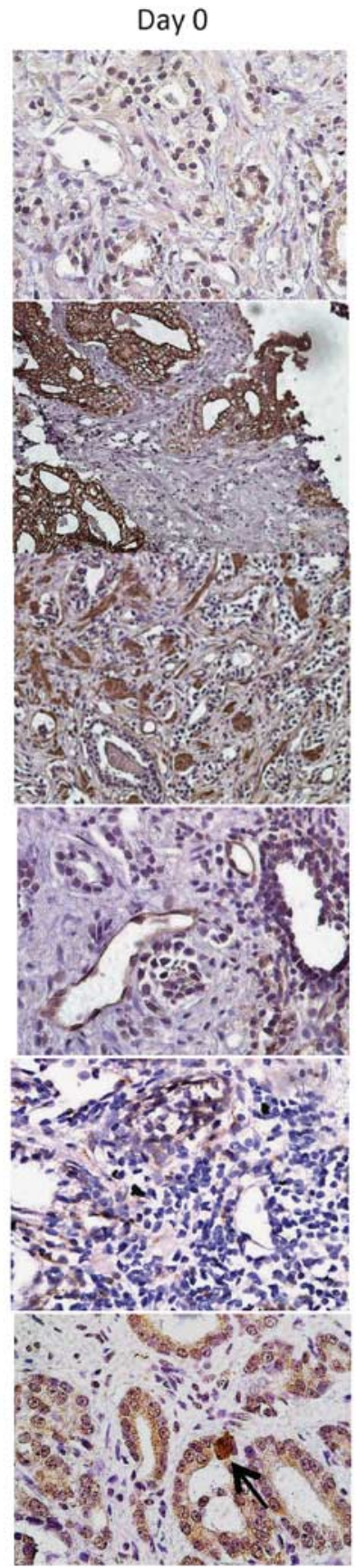

Day 5

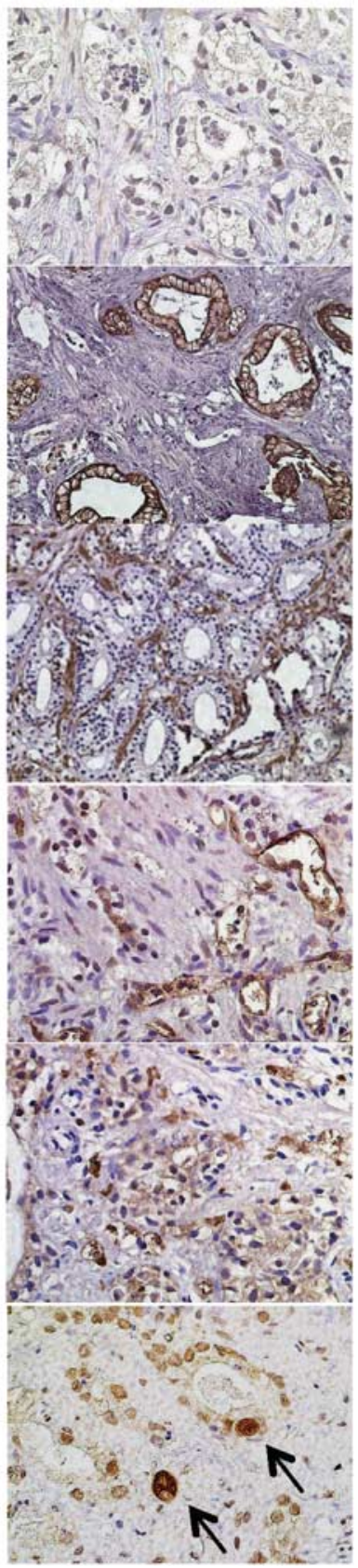

Figure 4 Cellular compositions of benign and prostate cancer (PCa) tissue slice cultures (TSCs). Cellular markers of basal epithelial cells (p63), luminal epithelial cells and cancer cells (cytokeratin 18; CK18), stromal cells (smooth muscle $\alpha$-actin; SMA), endothelial cells (CD31), inflammatory cells (CD68), and neuroendocrine cells (SYP, arrows) were appropriately expressed in benign and PCa TSCs after 5 days in culture. The expression patterns recapitulated those in the native 'day 0 ' tissues. Representative images were from patient specimens number 16,18 , and 27.

benign and cancer TSCs in the absence of androgen (Figure 6c). Quantification of the percent positively stained nuclei from six random $\times 40$ fields (average of 90 nuclei per field) from each of three tissue slices per condition confirmed statistically significant increases in apoptotic cells in benign and PCa TSCs in the absence of androgen (Figure 6d). There was a statistically significant reduction in Ki67-positive cells in PCa but not benign TSCs in the absence of androgen (Figure 6d). Further, intensity of PSA, an androgen-regulated gene, diminished in both benign and cancer TSCs as expected (Figure 6c). Together, these results show the androgen dependency of both benign prostate and primary PCa TSCs, further supporting the biological relevance of the TSC model to the human prostate. 


\section{TSCs Validate a Cancer-Specific Response to Piperlongumine}

Investigations to assess the feasibility of using TSC as a predictive preclinical model for human therapeutic response are ongoing across a variety of organ types. ${ }^{7,49,50}$ Of particular value is the ability to compare responses of cancer versus benign cells in TSCs, as efforts to identify cancer-specific drugs with reduced side effects intensify. The naturally derived alkaloid PL was recently found to selectively kill cancer cells across a range of cell lines and in a transgenic mouse model for breast cancer. ${ }^{51}$ Golovine et a ${ }^{28}$ subsequently tested the effects of PL on PCa cell lines and reported that after only 3-6 h, PL depleted AR and reduced cell proliferation. There remains the question of whether the effects of PL on PCa cell lines will be recapitulated in the native prostatic microenvironment and whether PL will affect benign prostate cells as well as the cancer. After confirming the androgen dependence of benign and PCa TSCs, we evaluated the effects of PL in this more biologically relevant system in which we can compare benign and cancer responses.

Six-hour treatment with low-dose PL $(10 \mu \mathrm{m})$ appeared to reduce viability and cause epithelial degeneration to a somewhat greater extent in cancer TSCs than in benign as evidenced by MTS assays and $\mathrm{H} \& \mathrm{E}$ staining, respectively (Figure $7 \mathrm{a}$ and $\mathrm{b}$ ). We next used IHC to localize cell-specific effects of PL in the benign and cancer TSCs. AR expression persisted in benign TSCs after $6 \mathrm{~h}$ of PL treatment, whereas AR was significantly reduced in PL-treated PCa TSCs (Figure 7c and d). Further, while there was a slight decrease in actively proliferating (Ki67-positive) cells in the PL-treated PCa TSCs, there was a significant increase in PCa cells undergoing apoptosis (CC3-positive) compared with benign cells (Figure $7 \mathrm{c}$ and $\mathrm{d}$ ). These results are consistent with and validate the findings by Golovine et $a l^{28}$ (although they did not test for apoptosis), while additionally revealing a cancerspecific effect of PL in the prostate that is consistent with findings in other tissue types. ${ }^{51}$ These findings lend support for further investigation into the use of PL in the clinic, and they exemplify the utility of the TSC model for validating preclinical studies previously executed only in cell lines or animal models.

\section{DISCUSSION}

Optimization of culture conditions resulted in maintenance of benign and malignant prostate TSCs for 5 days, a significant improvement over our previous ability to maintain TSCs for only $\sim 2$ days without signs of degeneration. Although others have reportedly maintained prostate TSCs for up to a week, maintenance of structure and function was not comprehensively evaluated in those studies, and we could not reproduce those findings. We extended the longevity of TSCs by using a serum-free medium previously developed for primary culture of human prostatic epithelial cells, Complete PFMR-4A, and increasing the androgen supplement, R1881, from 10 to $50 \mathrm{nM}$. Although $50 \mathrm{nM}$ is a high dose of this synthetic androgen that is often used in cell culture because of its stability compared with the natural androgen, DHT, little is known about hormone dynamics in this experimental context. Changing the medium daily also contributed to increased survival of TSCs. Although perfusion culture might prove superior, ${ }^{37}$ frequent refreshment of medium is a feasible alternative when using standard culture apparati.

Why prostate tissues are so challenging to maintain in culture for long periods is unclear. TSCs from other species or organs can be maintained for weeks or months. ${ }^{7,25,27,52}$ Organotypic culture models of the human prostate and $\mathrm{PCa}$ have taken several forms in the past, but their uses have been hampered by a short lifespan, the need for technical optimization, and lack of thorough characterization to confirm fidelity and reproducibility.

Over the 5-day period of culture in optimized medium, the TSC model maintained the authentic structure, function, and biological characteristics of both the benign prostate and PCa. Basal cell hyperplasia and luminal cell degeneration were minimized and the characteristic single layer of basal cells topped by a layer of secretory luminal cells was preserved in benign epithelial glands. Classic cell-type expression of proteins was retained, as evidenced by the localization of p63 and CK5 to the basal cells and CK18, AR, and PSA to the luminal cells. Cancer-associated markers that are specifically or differentially expressed in PCa, including AMACR, TMPRSS2, PTEN, PSMA, and E-cadherin, were appropriately expressed in PCa TSCs. Neuroendocrine differentiation in both benign prostate and PCa TSCs was typical of that observed in native tissue. SMA expression confirmed the survival of smooth muscle cells and myofibroblasts in the stroma of benign tissue and $\mathrm{PCa}$, respectively. Comparable rates of proliferation and apoptosis were observed in TSCs and native tissues, as measured by labeling for Ki67 and CC3.

Recapitulation of the cellular and molecular phenotype of the native tissue is lacking in other in vitro models. Cellular and molecular heterogeneity, in addition to the presence of an intact microenvironment, are ultimately necessary for accurate preclinical evaluations. Our comprehensive characterization also showed for the first time that endothelial cells, macrophages, and monocytes survive in prostate TSCs. The presence of these cells may enable preclinical studies of therapeutics targeting the vascular or the immune system.

A notable outcome of optimizing culture conditions was our ability to maintain PCa of different Gleason grades in TSCs. There is a pressing need for model systems that authentically represent low-risk (Gleason grade 3 ) and high-risk (Gleason grades 4/5) primary human $\mathrm{PCa}$, as the latter is associated with a high risk of recurrence and current neoadjuvant therapies have not significantly extended overall survival. ${ }^{53}$ TSCs can fulfill this need, as all Gleason grades were maintained during the 5-day culture period and can be used to screen novel therapies. Further, PCa-derived TSCs often contain admixed benign glands, uniquely providing an internal control for evaluating cancer specificity and 
BENIGN

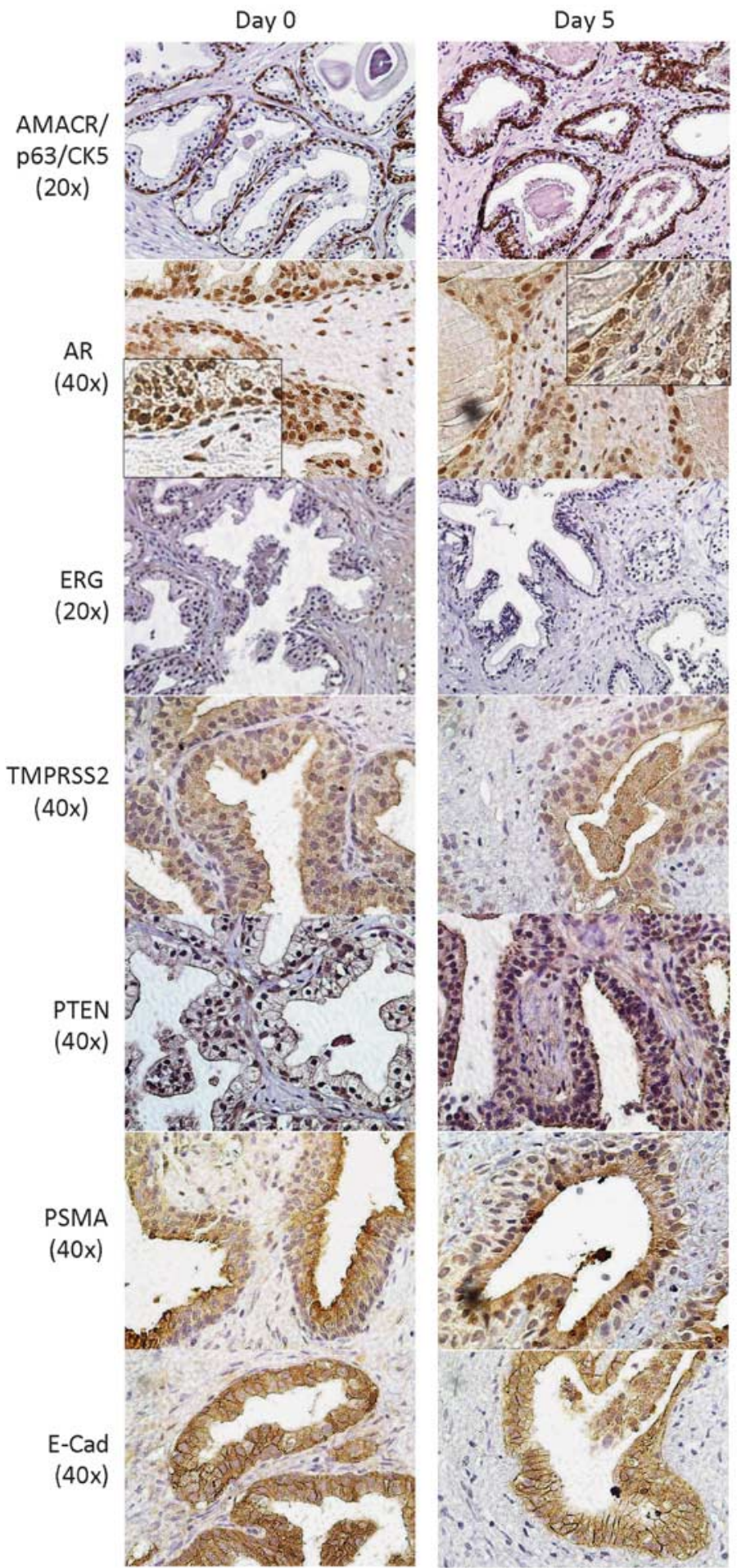

CANCER

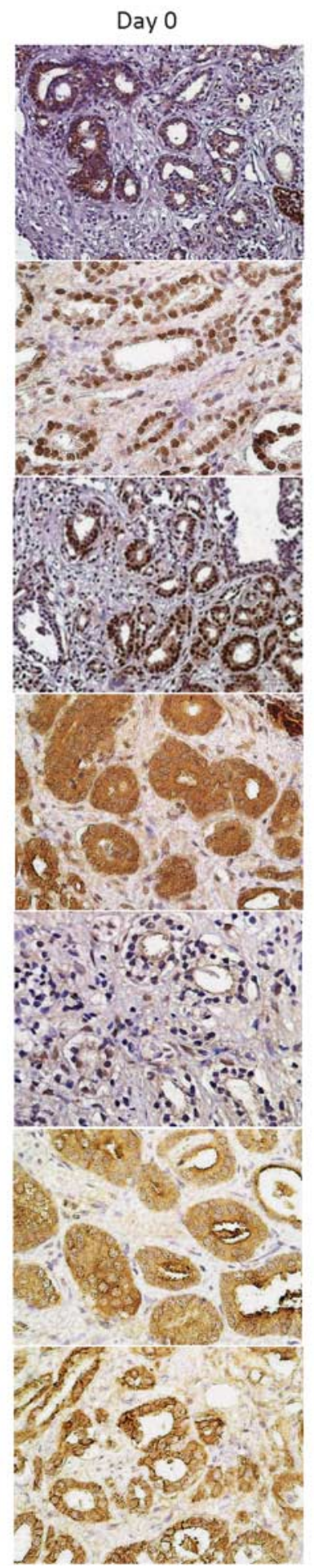

Day 5

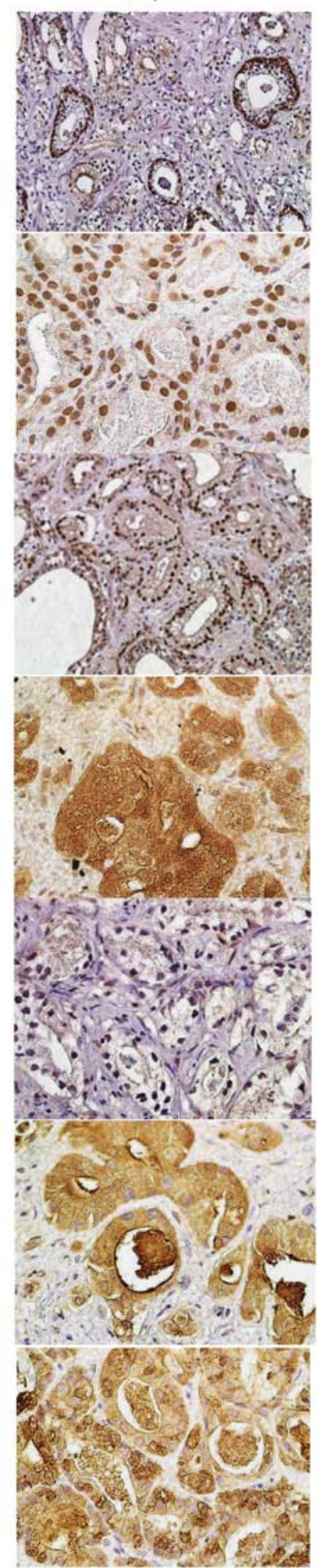

Figure 5 Biomarker expression in benign and prostate cancer (PCa) tissue slice cultures (TSCs). Immunohistochemistry (IHC) expression patterns of known biomarkers in benign and PCa TSCs cultured for 5 days mirrored those in the corresponding native 'day 0 ' tissues. A $\times 60$-magnification inserts show the absence of androgen receptor (AR) staining in basal cells of benign TSCs. Representative images were from patient specimens number 18,27 , and 28.

mechanisms of experimental therapeutics. Taking advantage of this feature, we tested the activity of the natural agent PL that reportedly reduces AR expression in a cancer-specific manner. ${ }^{28}$ We validated this finding in the TSC model, supporting further investigation into the efficacy of PL in the clinical setting. 
a

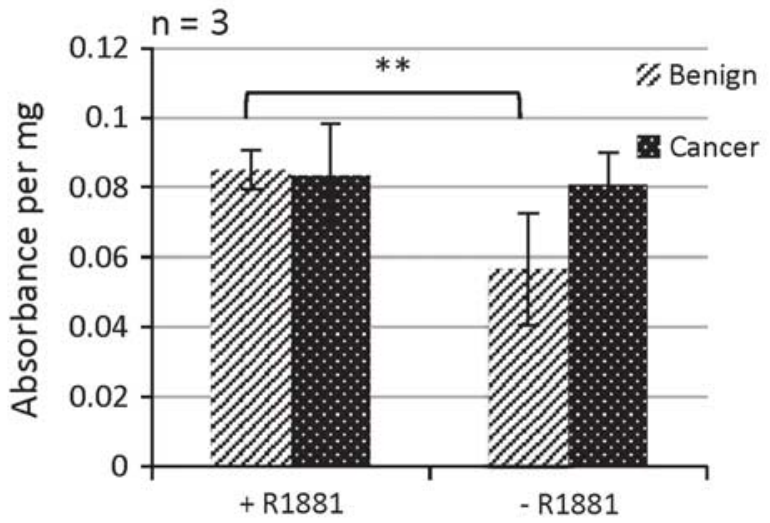

C

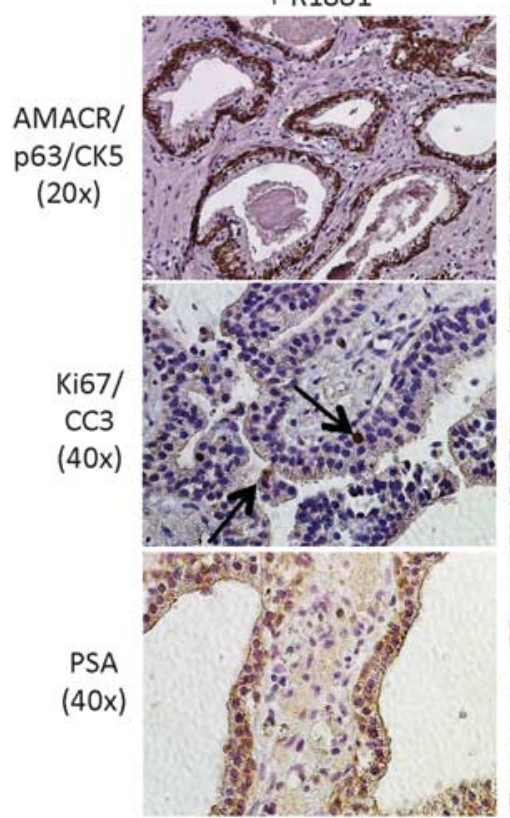

b

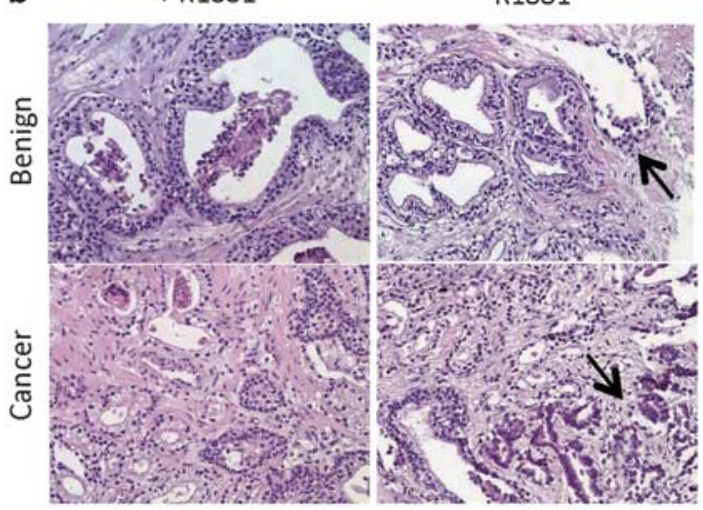

CANCER

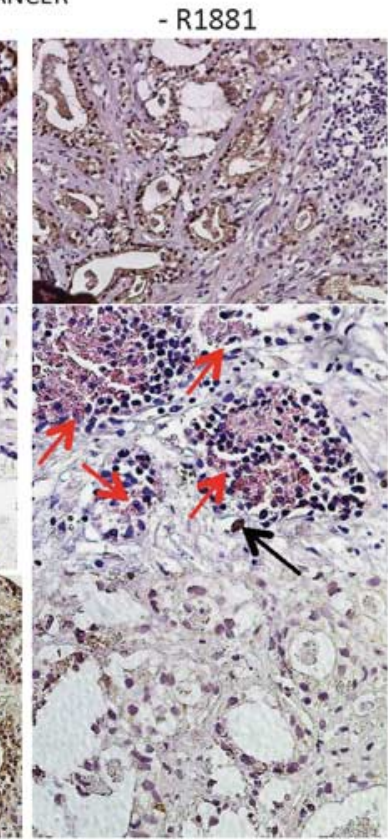

d

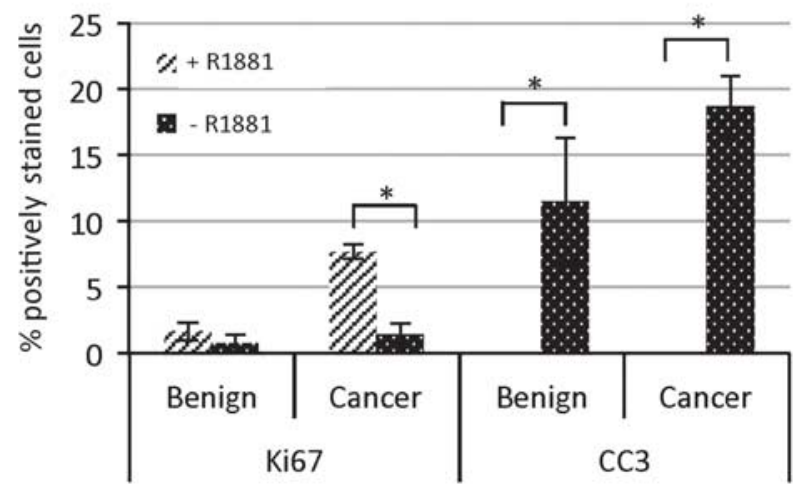

Figure 6 Responses of tissue slice cultures (TSCs) to androgen ablation. Culture of benign and prostate cancer (PCa) TSCs in the absence of androgen for 5 days resulted in heterogeneous reduction of cellular viability and glandular integrity according to MTS assays (a) and hematoxylin and eosin (H\&E) staining (b, arrows point to degenerating glands), respectively. Luminal degeneration was also evident upon immunohistochemistry (IHC) evaluation of benign and PCa TSCs cultured for 5 days in the absence (ethanol control) of R1881 (c). Benign and PCa TSCs were verified by $\alpha$-methylacyl coenzyme A racemase (AMACR)/p63/cytokeratin 5 (CK5) staining (top row). Androgen ablation reduced the number of actively proliferating cells (Ki67 positive, black arrows) and increased the number of cells undergoing apoptosis (cleaved caspase 3 (CC3) positive, red arrows) in both benign and PCa TSCs. Prostatespecific antigen (PSA) expression was reduced in both benign and PCa TSCs upon 5 days of androgen ablation (bottom row). (d) The percentages of CC3- and Ki67-positive nuclei were quantified from six random $\times 40$ fields from each of three tissue slices per condition (average of 90 nuclei per field). ${ }^{*} P<0.05,{ }^{*} P<0.01$. Experiments and representative images were from patient specimens number 18,20 , and 21. 
a

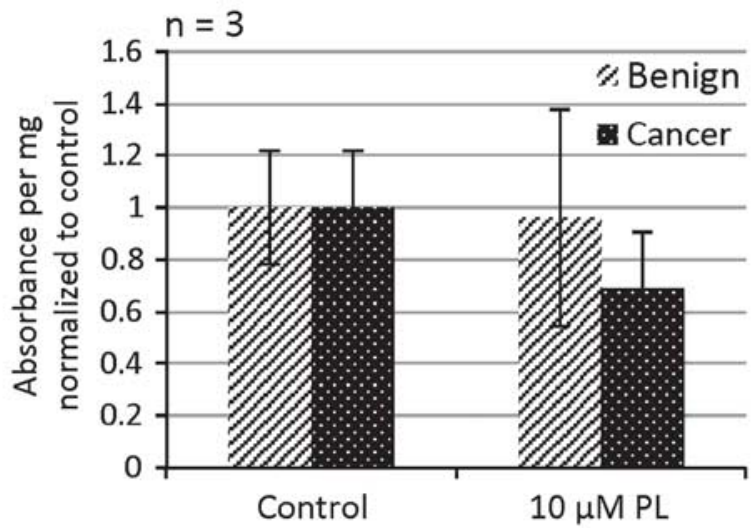

c

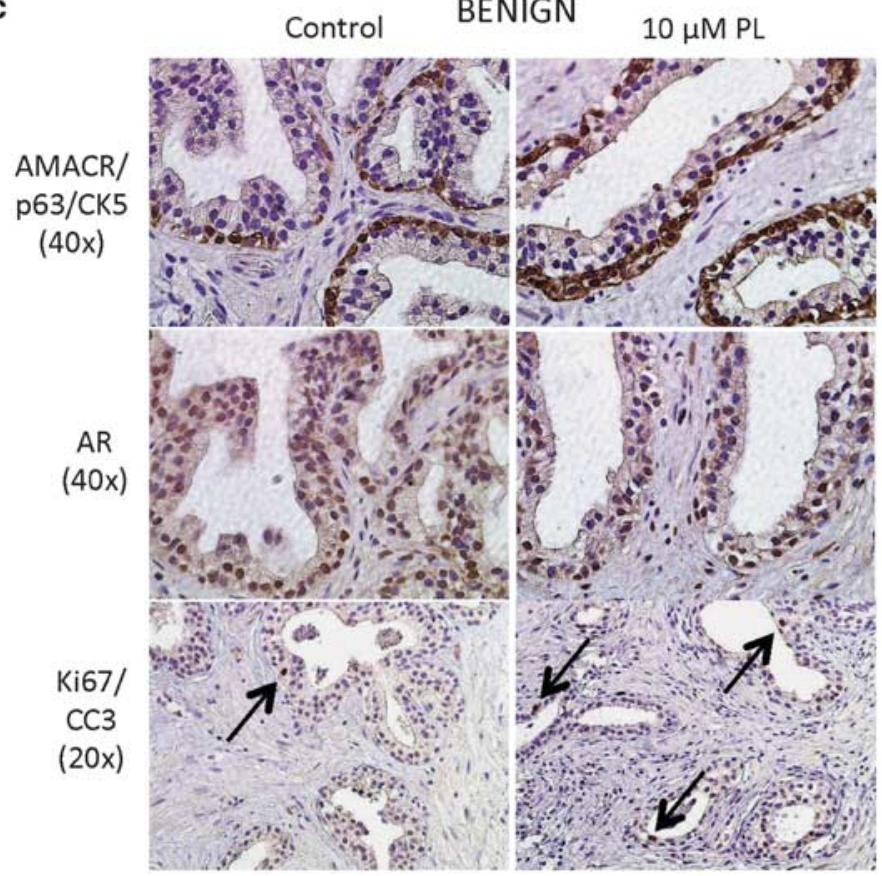

b

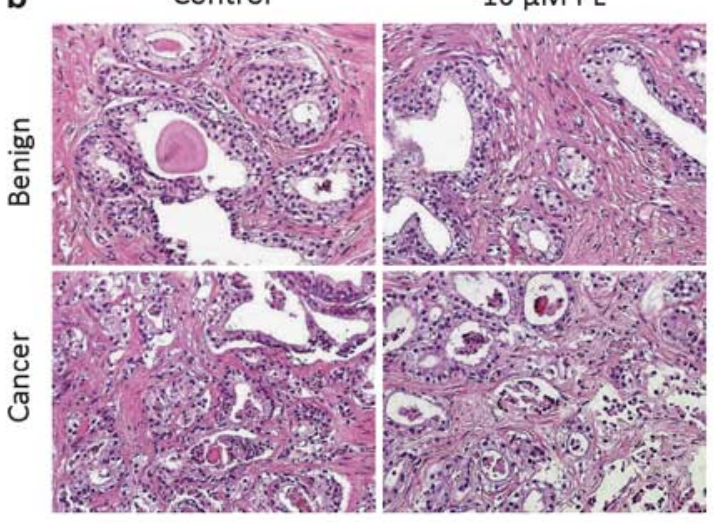

Control CANCER $10 \mu \mathrm{M} \mathrm{PL}$

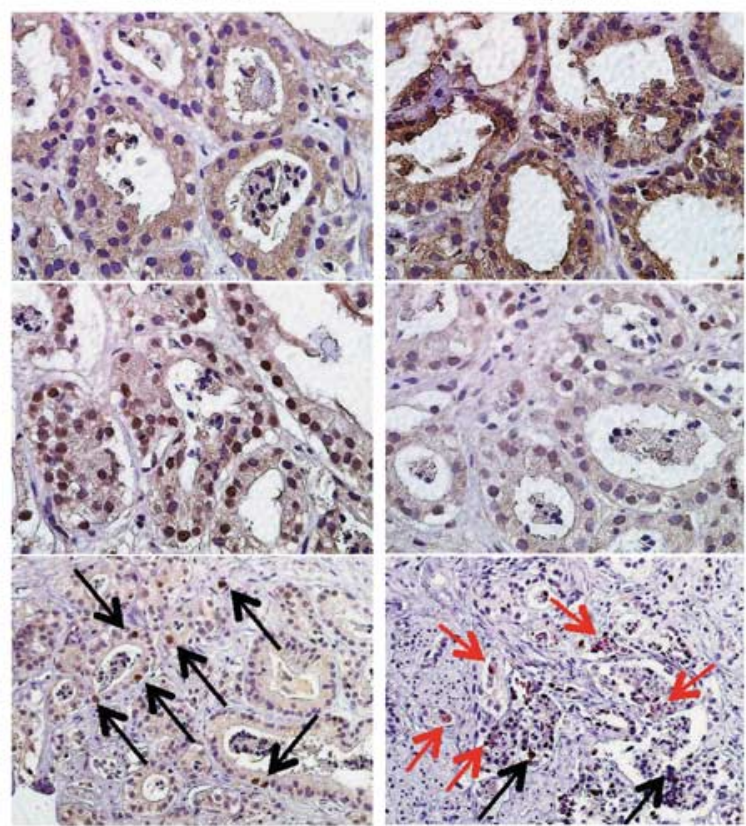

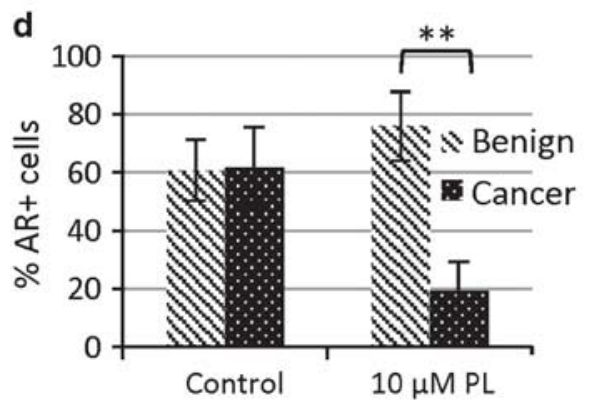
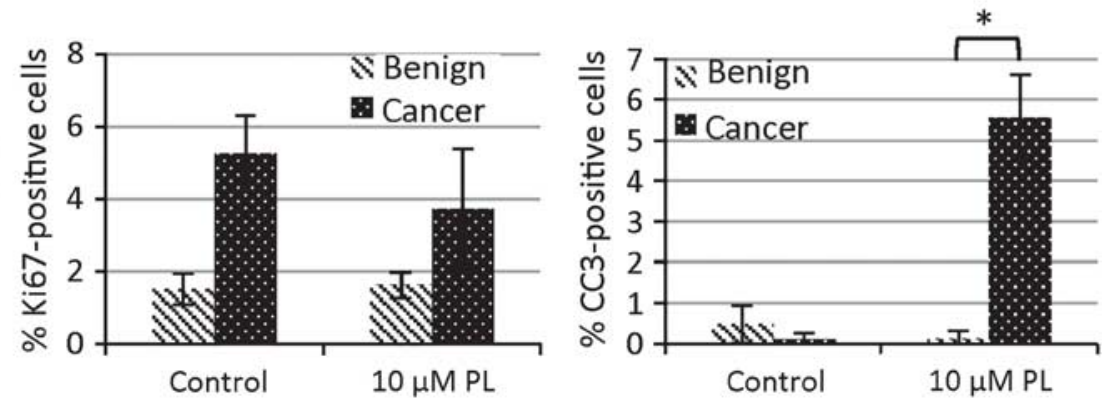

Figure 7 Responses of tissue slice cultures (TSCs) to piperlongumine (PL). Prostate cancer (PCa) but not benign TSCs treated with PL for $6 \mathrm{~h}$ exhibited a nonsignificant reduction of viability (MTS assay, a) that was mirrored by sporadic regions of luminal degeneration (hematoxylin and eosin (H\&E), b). Further immunohistochemistry (IHC) evaluation of benign and PCa TSCs revealed a cancer-specific decrease of androgen receptor (AR) expression (middle row $\mathbf{c}, \mathbf{d}$ ) and increase of apoptotic cells (red arrows, bottom row $\mathbf{c}, \mathbf{d}$ ). PL treatment did not significantly affect proliferation among benign or PCa cells (black arrows, bottom row c, d). Total nuclei (average of 114 per field) and positively stained nuclei were blindly counted from three random $\times 40$ fields from each of three tissue slices per treatment $(\mathbf{d}) .{ }^{*} P<0.01$, ${ }^{*} P<0.001$. Experiments and representative images were from patient specimen number 26.

The androgen dependence that we demonstrated in TSCs is an essential characteristic of an authentic model of the benign and malignant prostate, especially considering that targeting the AR signaling pathway is a major goal in PCa research and therapy. However, further investigation into the mechanism of androgen signaling in TSCs will be necessary. 
Although expression of the androgen-regulated genes TMPRSS2 and PSA persisted in TSCs, ERG expression (presumably driven by the androgen-responsive promoter of the TMPRSS2-ERG gene fusion) waned. AR signaling dynamics have not yet been investigated in this model system, and persistence of target gene expression may be due to longer half-lives instead of active AR signaling. Regardless, the presence of androgen proved to be critical for maintenance of benign and PCa TSCs.

The faithful retention of tissue structure and function in the TSC model presents an ideal opportunity to evaluate multifaceted effects of therapeutic compounds on an organ. ${ }^{15}$ TSC may be used to identify potential biomarkers of drug response, determine drug concentrations that affect organ function or morphology, carry out gene or protein expression profiling, identify species-specific or cell-line-specific effects, and elucidate mechanisms relevant to human safety. ${ }^{49} \mathrm{~A}$ recent study evaluated a new HSP90 inhibitor in PCa cell lines and organotypic PCa tissue cultures and reported that the tissue cultures provided information on the drug response that was not previously observed in cell lines or animal models. ${ }^{50}$ Further studies testing the boundaries of preclinical assessment with TSCs are warranted.

Supplementary Information accompanies the paper on the Laboratory Investigation website (http://www.laboratoryinvestigation.org)

\section{ACKNOWLEDGMENTS}

This work was supported in part with funding from NIH 2T32DK007217-37, DAMD W81XWH-10-1-0336, and DAMD W81XWH-13-1-0268.

\section{DISCLOSURE/CONFLICT OF INTEREST}

The authors declare no conflict of interest.

1. Pienta KJ, Abate-Shen C, Agus DB, et al. The current state of preclinical prostate cancer animal models. Prostate 2008;68:629-639.

2. Toivanen R, Taylor RA, Pook DW, et al. Breaking through a roadblock in prostate cancer research: an update on human model systems. J Steroid Biochem Mol Biol 2012;131:122-131.

3. Taylor RA, Risbridger GP. Prostatic tumor stroma: a key player in cancer progression. Current Cancer Drug Targets 2008;8:490-497.

4. Shappell SB, Thomas GV, Roberts RL, et al. Prostate pathology of genetically engineered mice: definitions and classification. The consensus report from the Bar Harbor meeting of the Mouse Models of Human Cancer Consortium Prostate Pathology Committee. Cancer Res 2004;64:2270-2305.

5. Peehl DM. Primary cell cultures as models of prostate cancer development. Endocr Relat Cancer 2005;12:19-47.

6. Parrish AR, Gandolfi AJ, Brendel K. Precision-cut tissue slices: applications in pharmacology and toxicology. Life Sci 1995;57: 1887-1901.

7. Holliday DL, Moss MA, Pollock S, et al. The practicalities of using tissue slices as preclinical organotypic breast cancer models. J Clin Pathol 2013:66:253-255

8. Fisher RL, Vickers AE. Preparation and culture of precision-cut organ slices from human and animal. Xenobiotica 2013;43:8-14.

9. Enk CD, Jacob-Hirsch J, Gal H, et al. The UVB-induced gene expression profile of human epidermis in vivo is different from that of cultured keratinocytes. Oncogene 2006;25:2601-2614.

10. Schmid JO, Dong M, Haubeiss S, et al. Cancer cells cue the p53 response of cancer-associated fibroblasts to cisplatin. Cancer Res 2012;72:5824-5832.
11. Jacobs ER, Bodiga S, Ali I, et al. Tissue protection and endothelial cell signaling by $20-\mathrm{HETE}$ analogs in intact ex vivo lung slices. Exp Cell Res 2012;318:2143-2152.

12. Brauer HA, Makowski L, Hoadley KA, et al. Impact of tumor microenvironment and epithelial phenotypes on metabolism in breast cancer. Clin Cancer Res 2013;19:571-585.

13. Graaf IA, Groothuis GM, Olinga P. Precision-cut tissue slices as a tool to predict metabolism of novel drugs. Exp Opin Drug Metab Toxicol 2007:3:879-898.

14. Keshari KR, Sriram R, Van Criekinge M, et al. Metabolic reprogramming and validation of hyperpolarized $13 \mathrm{C}$ lactate as a prostate cancer biomarker using a human prostate tissue slice culture bioreactor. Prostate 2013;73:1171-1181.

15. Vaira V, Fedele G, Pyne S, et al. Preclinical model of organotypic culture for pharmacodynamic profiling of human tumors. Proc Natl Acad Sci USA 2010;107:8352-8356.

16. Varani J, Dame MK, Wojno K, et al. Characteristics of nonmalignant and malignant human prostate in organ culture. Lab Invest 1999;79: 723-731.

17. Papini S, Rosellini A, Campani D, et al. Selective growth of epithelial basal cells from human prostate in a three-dimensional organ culture. Prostate 2004;59:383-392.

18. Parrish AR, Sallam K, Nyman DW, et al. Culturing precision-cut human prostate slices as an in vitro model of prostate pathobiology. Cell Biol Toxicol 2002;18:205-219.

19. Blauer M, Tammela TL, Ylikomi T. A novel tissue-slice culture model for non-malignant human prostate. Cell Tissue Res 2008;332:489-498.

20. Ni X, Zhang Y, Ribas J, et al. Prostate-targeted radiosensitization via aptamer-shRNA chimeras in human tumor xenografts. J Clin Invest 2011;121:2383-2390.

21. Kiviharju-af Hallstrom TM, Jaamaa $S$, Monkkonen $M$, et al. Human prostate epithelium lacks Wee1A-mediated DNA damage-induced checkpoint enforcement. Proc Natl Acad Sci USA 2007;104:7211-7216.

22. Jaamaa S, Af Hallstrom TM, Sankila A, et al. DNA damage recognition via activated ATM and p53 pathway in nonproliferating human prostate tissue. Cancer Res 2010;70:8630-8641.

23. Zhu L, Jaamaa S, Af Hallstrom TM, et al. PSA forms complexes with alpha(1) -antichymotrypsin in prostate. Prostate 2013;73:219-226.

24. Jaamaa S, Sankila A, Rantanen V, et al. Contrasting DNA damage checkpoint responses in epithelium of the human seminal vesicle and prostate. Prostate 2012;72:1060-1070.

25. Behrsing HP, Vickers AE, Tyson CA. Extended rat liver slice survival and stability monitored using clinical biomarkers. Biochem Biophys Res Commun 2003;312:209-213.

26. Amin K, Ip C, Sato B, et al. Characterization of ANIT-induced toxicity using precision-cut rat and dog liver slices cultured in a dynamic organ roller system. Toxicolo Pathol 2006;34:776-784.

27. Ahlgren $\mathrm{H}$, Henjum $\mathrm{K}$, Ottersen $\mathrm{OP}$, et al. Validation of organotypical hippocampal slice cultures as an ex vivo model of brain ischemia: different roles of NMDA receptors in cell death signalling after exposure to NMDA or oxygen and glucose deprivation. Cell Tissue Res 2011:345:329-341.

28. Golovine KV, Makhov PB, Teper E, et al. Piperlongumine induces rapid depletion of the androgen receptor in human prostate cancer cells. Prostate 2013;73:23-30.

29. Krumdieck CL. Development of a live tissue microtome: reflections of an amateur machinist. Xenobiotica 2013;43:2-7.

30. Peehl DM. Human prostatic epithelial cells. In: Freshney R, Freshney M (eds). Culture of Epithelial Cells. 2nd edn., New York, NY, USA, 2002, pp 171-194.

31. Zhao $\mathrm{H}$, Nolley $\mathrm{R}$, Chen $\mathrm{Z}$, et al. Tissue slice grafts: an in vivo model of human prostate androgen signaling. Am J Pathol 2010;177: 229-239.

32. Sun L, Gu L, Wang S, et al. N-acetylcysteine protects against apoptosis through modulation of group I metabotropic glutamate receptor activity. PLoS ONE 2012;7:e32503.

33. Krause MS, McClenaghan NH, Flatt PR, et al. L-arginine is essential for pancreatic beta-cell functional integrity, metabolism and defense from inflammatory challenge. J Endocrinol 2011;211:87-97.

34. Ghoumari AM, Dusart I, El-Etr M, et al. Mifepristone (RU486) protects Purkinje cells from cell death in organotypic slice cultures of postnatal rat and mouse cerebellum. Proc Natl Acad Sci USA 2003;100:7953-7958. 
35. Tilles AW, Baskaran $\mathrm{H}$, Roy $\mathrm{P}$, et al. Effects of oxygenation and flow on the viability and function of rat hepatocytes cocultured in a microchannel flat-plate bioreactor. Biotechnol Bioeng 2001;73: 379-389.

36. Rambani K, Vukasinovic J, Glezer A, et al. Culturing thick brain slices: an interstitial 3D microperfusion system for enhanced viability. J Neurosci Methods 2009;180:243-254.

37. Schumacher K, Khong YM, Chang S, et al. Perfusion culture improves the maintenance of cultured liver tissue slices. Tissue Eng 2007; 13:197-205.

38. Dabir PD, Ottosen P, Hoyer S, et al. Comparative analysis of three- and two-antibody cocktails to AMACR and basal cell markers for the immunohistochemical diagnosis of prostate carcinoma. Diagn Pathol 2012;7:81.

39. Cunha GR, Hayward SW, Wang YZ. Role of stroma in carcinogenesis of the prostate. Differentiation 2002;70:473-485.

40. De Nunzio C, Kramer G, Marberger $M$, et al. The controversial relationship between benign prostatic hyperplasia and prostate cancer: the role of inflammation. Eur Urol 2011;60:106-117.

41. Bigler SA, Deering RE, Brawer MK. Comparison of microscopic vascularity in benign and malignant prostate tissue. Hum Pathol 1993; 24:220-226.

42. di Sant'Agnese PA. Neuroendocrine differentiation in prostatic carcinoma: an update on recent developments. Ann Oncol 2001, 12(Suppl 2):S135-S140.

43. Tomlins SA, Rhodes DR, Perner $\mathrm{S}$, et al. Recurrent fusion of TMPRSS2 and ETS transcription factor genes in prostate cancer. Science 2005 310:644-648.
44. Chaux A, Albadine R, Toubaji A, et al. Immunohistochemistry for ERG expression as a surrogate for TMPRSS2-ERG fusion detection in prostatic adenocarcinomas. Am J Surg Pathol 2011;35:1014-1020.

45. Kwabi-Addo B, Giri D, Schmidt K, et al. Haploinsufficiency of the Pten tumor suppressor gene promotes prostate cancer progression. Proc Natl Acad Sci USA 2001;98:11563-11568.

46. McMenamin ME, Soung P, Perera $\mathrm{S}$, et al. Loss of PTEN expression in paraffin-embedded primary prostate cancer correlates with high Gleason score and advanced stage. Cancer Res 1999;59:4291-4296.

47. Wright Jr GL, Haley C, Beckett ML, et al. Expression of prostate-specific membrane antigen in normal, benign, and malignant prostate tissues. Urol Oncol 1995;1:18-28.

48. Jaggi $\mathrm{M}$, Johansson $\mathrm{SL}$, Baker JJ, et al. Aberrant expression of E-cadherin and beta-catenin in human prostate cancer. Urol Oncol 2005;23:402-406.

49. Vickers $A E$, Fisher RL. Evaluation of drug-induced injury and human response in precision-cut tissue slices. Xenobiotica 2013;43:29-40.

50. Centenera MM, Gillis JL, Hanson AR, et al. Evidence for efficacy of new Hsp90 inhibitors revealed by ex vivo culture of human prostate tumors. Clin Cancer Res 2012;18:3562-3570.

51. Raj L, Ide T, Gurkar AU, et al. Selective killing of cancer cells by a small molecule targeting the stress response to ROS. Nature 2011;475:231-234.

52. Meneghel-Rozzo T, Rozzo A, Poppi $L$, et al. In vivo and in vitro development of mouse pancreatic beta-cells in organotypic slices. Cell Tissue Res 2004;316:295-303.

53. Sonpavde G, Palapattu GS. Neoadjuvant therapy preceding prostatectomy for prostate cancer: rationale and current trials. Exp Rev Anticancer Ther 2010;10:439-450. 


\section{TITLES AND LEGENDS TO SUPPLEMENTARY FIGURES AND TABLES}

Figure S1 Example of histological verification upon slicing. Adjacent PCa tissue slices were frozen or underwent FFPE and sectioned for histological verification by H\&E (“Day 0"), or were cultured as TSCs. After 5 days in culture, TSCs underwent FFPE, sectioning, and H\&E staining ("Day 5"), revealing histological patterns that corresponded to the adjacent frozen and FFPE slices taken on Day 0. Representative images were from patient specimen \#30.

Figure S2. Representative negative controls for IHC. Negative control sections underwent immunohistochemical processing as described but were incubated in 1\% bovine serum albumin/phosphate buffered saline (vehicle control) during the primary antibody incubation step. Representative images were from patient specimen \#18.

Figure S3. Benign and malignant TSC histology over time in culture. H\&E staining revealed maintenance of benign and malignant tissue out to 5 days in culture upon increasing the R1881 to $50 \mathrm{nM}$ and changing the media daily. Representative images were from patient specimens \#4, 10, and 27.

Table S1. Patient and corresponding tissue slice culture summary.

Table S2. Prevalence of histological patterns in prostate TSCs cultured for 5 days. 
Figure S1
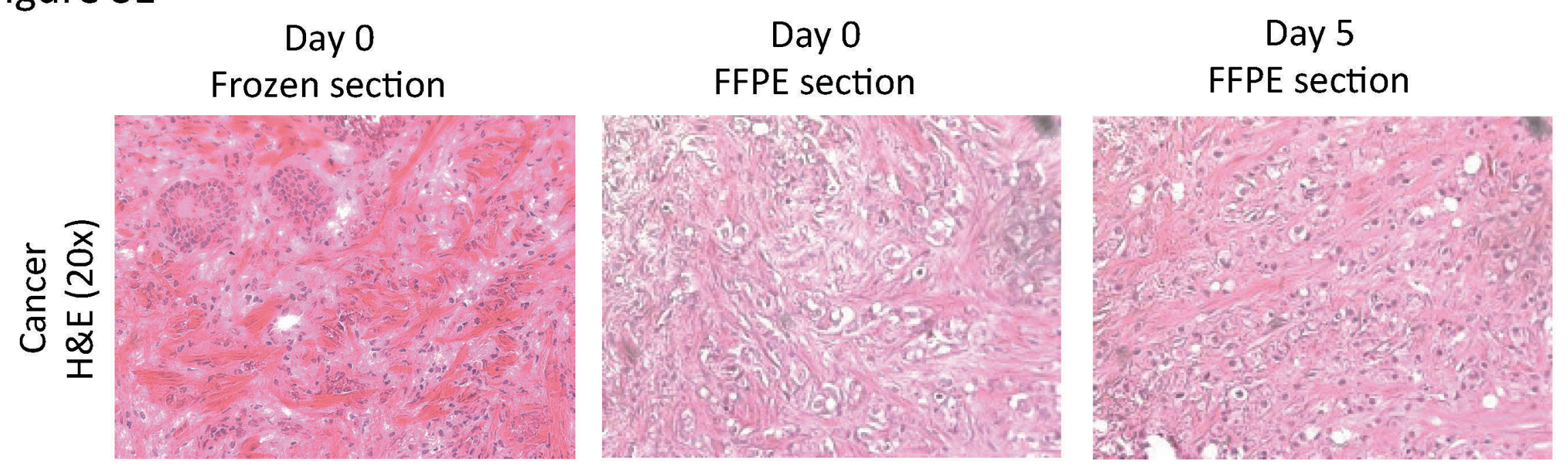


\section{Figure S2}

\section{$20 x$}

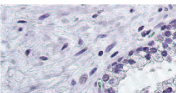

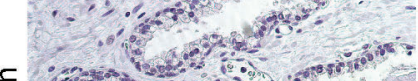

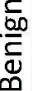

$\frac{5}{6}$

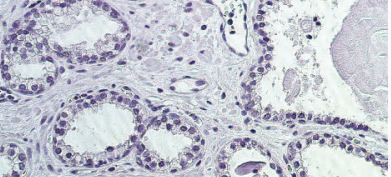

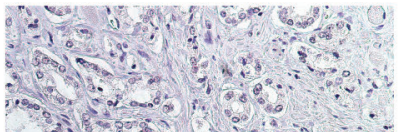

$\frac{1}{0}$

3

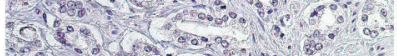

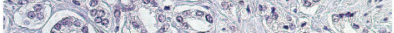
50 (v)

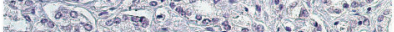
3.

\section{$40 x$}
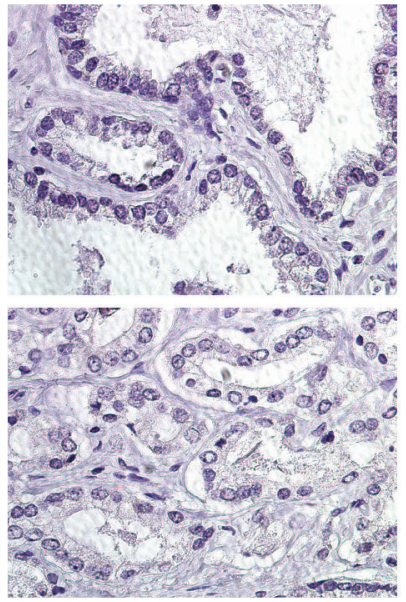


\section{Figure S3}

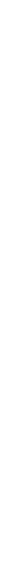


Table S1. Patient and corresponding tissue slice culture summary.

\begin{tabular}{|c|c|c|c|c|c|c|c|}
\hline Patient \# & Age & \# slices & $\begin{array}{l}\text { Days in } \\
\text { culture }\end{array}$ & Culture medium & Degeneration $>25 \%{ }^{1}$ & Hyperproliferation $>\mathbf{2 5} \%^{2}$ & TSC pathology \\
\hline 1 & 53 & 3 & 3 & PFMR4A $10 \mathrm{nM}^{3}$ & $\mathrm{Y}$ & $\mathrm{N}$ & Benign \\
\hline \multirow[t]{2}{*}{2} & 70 & 3 & 2 & PFMR4A $10 \mathrm{nM}$ & $\mathrm{Y}$ & $\mathrm{N}$ & Benign \\
\hline & & 3 & 3 & PFMR4A $10 \mathrm{nM}$ & $\mathrm{Y}$ & $\mathrm{N}$ & Benign \\
\hline \multirow[t]{6}{*}{3} & 52 & 3 & 2 & PFMR4A $10 \mathrm{nM}$ & $\mathrm{N}$ & $\mathrm{N}$ & Benign \\
\hline & & 3 & 2 & PFMR4A $50 \mathrm{nM}^{4}$ & $\mathrm{~N}$ & $\mathrm{~N}$ & Benign \\
\hline & & 3 & 2 & PFMR4A $100 \mathrm{nM}^{5}$ & $\mathrm{~N}$ & $\mathrm{~N}$ & Benign \\
\hline & & 3 & 3 & PFMR4A $10 \mathrm{nM}$ & $\mathrm{Y}$ & $\mathrm{N}$ & Benign \\
\hline & & 3 & 3 & PFMR4A $50 \mathrm{nM}$ & $\mathrm{N}$ & $\mathrm{N}$ & Benign \\
\hline & & 3 & 3 & PFMR4A $100 \mathrm{nM}$ & $\mathrm{N}$ & $\mathrm{N}$ & Benign \\
\hline \multirow{6}{*}{4} & 72 & 3 & 2 & PFMR4A $10 \mathrm{nM}$ & $\mathrm{Y}$ & $\mathrm{Y}$ & Benign \\
\hline & & 3 & 2 & PFMR4A $50 \mathrm{nM}$ & $\mathrm{N}$ & $\mathrm{N}$ & Benign \\
\hline & & 3 & 2 & PFMR4A $100 \mathrm{nM}$ & $\mathrm{N}$ & $\mathrm{N}$ & Benign \\
\hline & & 3 & 3 & PFMR4A $10 \mathrm{nM}$ & $\mathrm{Y}$ & $\mathrm{N}$ & Benign \\
\hline & & 3 & 3 & PFMR4A $50 \mathrm{nM}$ & $\mathrm{N}$ & $\mathrm{N}$ & Benign \\
\hline & & 3 & 3 & PFMR4A $100 \mathrm{nM}$ & $\mathrm{N}$ & $\mathrm{N}$ & Benign \\
\hline \multirow[t]{2}{*}{5} & 58 & 6 & 3 & PFMR4A $50 \mathrm{nM}$ & $\mathrm{N}$ & $\mathrm{N}$ & Benign \\
\hline & & 6 & 4 & PFMR4A $50 \mathrm{nM}$ & $\mathrm{Y}$ & $\mathrm{N}$ & Benign \\
\hline \multirow[t]{4}{*}{6} & 69 & 3 & 3 & PFMR4A $50 \mathrm{nM}$ & $\mathrm{Y}$ & $\mathrm{N}$ & Benign \\
\hline & & 3 & 3 & PFMR4A $100 \mathrm{nM}$ & $\mathrm{Y}$ & $\mathrm{N}$ & Benign \\
\hline & & 3 & 4 & PFMR4A $50 \mathrm{nM}$ & $\mathrm{N}$ & $\mathrm{N}$ & Benign \\
\hline & & 3 & 4 & PFMR4A $100 \mathrm{nM}$ & $\mathrm{Y}$ & $\mathrm{N}$ & Benign \\
\hline \multirow[t]{4}{*}{7} & 67 & 3 & 3 & PFMR4A $50 \mathrm{nM}$ & $\mathrm{N}$ & $\mathrm{N}$ & Benign \\
\hline & & 3 & 3 & PFMR4A $100 \mathrm{nM}$ & $\mathrm{Y}$ & $\mathrm{N}$ & Benign \\
\hline & & 3 & 4 & PFMR4A $50 \mathrm{nM}$ & $\mathrm{N}$ & $\mathrm{N}$ & Benign \\
\hline & & 3 & 4 & PFMR4A $100 \mathrm{nM}$ & $\mathrm{Y}$ & $\mathrm{N}$ & Benign \\
\hline \multirow[t]{2}{*}{8} & 50 & 3 & 4 & PFMR4A $50 \mathrm{nM}$ & $\mathrm{Y}$ & $\mathrm{N}$ & Benign \\
\hline & & 3 & 5 & PFMR4A $50 \mathrm{nM}$ & $\mathrm{Y}$ & $\mathrm{N}$ & Benign \\
\hline \multirow[t]{2}{*}{9} & 58 & 3 & 4 & PFMR4A $50 \mathrm{nM}$ & $\mathrm{N}$ & N/A & $3^{11}$ \\
\hline & & 3 & 5 & PFMR4A $50 \mathrm{nM}$ & $\mathrm{N}$ & $\mathrm{N} / \mathrm{A}$ & 3 \\
\hline \multirow[t]{3}{*}{10} & 60 & 3 & 3 & PFMR4A $50 \mathrm{nM}$ & $\mathrm{N}$ & $\mathrm{N}$ & Benign \\
\hline & & 3 & 4 & PFMR4A $50 \mathrm{nM}$ & $\mathrm{N}$ & $\mathrm{N}$ & Benign \\
\hline & & 4 & 5 & PFMR4A $50 \mathrm{nM}$ & $\mathrm{N}$ & $\mathrm{N}$ & Benign \\
\hline \multirow[t]{2}{*}{11} & 56 & 2 & 5 & PFMR4A $50 \mathrm{nM}$ & $\mathrm{N}$ & $\mathrm{N}$ & Benign \\
\hline & & 2 & 5 & PFMR4A $50 \mathrm{nM}$ & $\mathrm{N}$ & N/A & 3 \\
\hline 12 & 72 & 3 & 2 & PFMR4A $50 \mathrm{nM}$ & $\mathrm{N}$ & $\mathrm{N}$ & Benign \\
\hline & & 3 & 4 & PFMR4A $50 \mathrm{nM}$ & $\mathrm{N}$ & $\mathrm{N}$ & Benign \\
\hline & & 6 & 5 & PFMR4A $50 \mathrm{nM}$ & $\mathrm{N}$ & $\mathrm{N}$ & Benign \\
\hline & & 3 & 2 & PFMR4A $10 \mathrm{nM}$ & $\mathrm{Y}$ & $\mathrm{N}$ & Benign \\
\hline & & 3 & 4 & PFMR4A $10 \mathrm{nM}$ & $\mathrm{Y}$ & $\mathrm{N}$ & Benign \\
\hline & & 3 & 5 & PFMR4A $10 \mathrm{nM}$ & $\mathrm{Y}$ & $\mathrm{Y}$ & Benign \\
\hline & & 3 & 2 & KSFM/M199 & $\mathrm{Y}$ & $\mathrm{Y}$ & Benign \\
\hline & & 3 & 4 & KSFM/M199 & $\mathrm{Y}$ & $\mathrm{Y}$ & Benign \\
\hline & & 3 & 5 & KSFM/M199 & $\mathrm{Y}$ & $\mathrm{Y}$ & Benign \\
\hline 13 & 64 & 2 & 2 & PFMR4A $50 \mathrm{nM}$ & $\mathrm{N}$ & N/A & $3+4$ \\
\hline & & 2 & 4 & PFMR4A $50 \mathrm{nM}$ & $\mathrm{Y}$ & $\mathrm{N} / \mathrm{A}$ & $3+3$ \\
\hline & & 4 & 5 & PFMR4A $50 \mathrm{nM}$ & $\mathrm{N}$ & N/A & $3+4$ \\
\hline 14 & 70 & 2 & 2 & PFMR4A $50 \mathrm{nM}$ & $\mathrm{Y}$ & $\mathrm{N}$ & Benign \\
\hline & & 2 & 4 & PFMR4A $50 \mathrm{nM}$ & $\mathrm{Y}$ & $\mathrm{N}$ & Benign \\
\hline & & 3 & 5 & PFMR4A $50 \mathrm{nM}$ & $\mathrm{Y}$ & $\mathrm{N}$ & Benign \\
\hline & & 2 & 2 & PFMR4A $10 \mathrm{nM}$ & $\mathrm{Y}$ & $\mathrm{N}$ & Benign \\
\hline & & 2 & 4 & PFMR4A $10 \mathrm{nM}$ & $\mathrm{N}$ & $\mathrm{Y}$ & Benign \\
\hline & & 3 & 5 & PFMR4A $10 \mathrm{nM}$ & $\mathrm{Y}$ & $\mathrm{N}$ & Benign \\
\hline & & 2 & 2 & KSFM/M199 & $\mathrm{Y}$ & $\mathrm{N}$ & Benign \\
\hline & & 2 & 4 & KSFM/M199 & $\mathrm{Y}$ & $\mathrm{N}$ & Benign \\
\hline & & 3 & 5 & KSFM/M199 & $\mathrm{Y}$ & $\mathrm{Y}$ & Benign \\
\hline 15 & 55 & 2 & 2 & PFMR4A $50 \mathrm{nM}$ & $\mathrm{N}$ & $\mathrm{N}$ & Benign \\
\hline & & 2 & 3 & PFMR4A $50 \mathrm{nM}$ & $\mathrm{N}$ & $\mathrm{N}$ & Benign \\
\hline & & 2 & 4 & PFMR4A $50 \mathrm{nM}$ & $\mathrm{N}$ & $\mathrm{N}$ & Benign \\
\hline 16 & 66 & 3 & 5 & PFMR4A $0 \mathrm{nM}^{7}$ & $\mathrm{Y}$ & $\mathrm{N}$ & Benign \\
\hline & & 3 & 5 & PFMR4A $50 \mathrm{nM}$ & $\mathrm{N}$ & $\mathrm{N}$ & Benign \\
\hline & & 5 & 5 & PFMR4A 0 nM & $\mathrm{N}$ & $\mathrm{N} / \mathrm{A}$ & 3 \\
\hline & & 5 & 5 & PFMR4A $50 \mathrm{nM}$ & $\mathrm{N}$ & $\mathrm{N} / \mathrm{A}$ & 3 \\
\hline 17 & 62 & 6 & 5 & KSFM/M199 & $\mathrm{N}$ & $\mathrm{Y}$ & Benign \\
\hline & & 6 & 5 & PFMR4A $10 \mathrm{nM}$ & $\mathrm{Y}$ & $\mathrm{Y}$ & Benign \\
\hline & & 8 & 5 & PFMR4A $50 \mathrm{nM}$ & Y & $\mathrm{Y}$ & Benign \\
\hline 18 & 62 & 6 & 5 & PFMR4A $0 \mathrm{nM}$ & $\mathrm{Y}$ & $\mathrm{N}$ & Benign \\
\hline & & 6 & 5 & PFMR4A $50 \mathrm{nM}$ & $\mathrm{N}$ & $\mathrm{N}$ & Benign \\
\hline & & 6 & 5 & PFMR4A 0 nM & $\mathrm{Y}$ & N/A & 3 \\
\hline & & 6 & 5 & PFMR4A $50 \mathrm{nM}$ & $\mathrm{N}$ & $\mathrm{N} / \mathrm{A}$ & 3 \\
\hline 19 & 60 & 4 & 5 & KSFM/M199 & $\mathrm{N} / \mathrm{A}$ & N/A & $\mathrm{N} / \mathrm{A}$ \\
\hline
\end{tabular}




\begin{tabular}{|c|c|c|c|c|c|c|c|}
\hline & & 4 & 5 & PFMR4A 10 nM & N/A & $\mathrm{N} / \mathrm{A}$ & N/A \\
\hline & & 8 & 5 & PFMR4A $50 \mathrm{nM}$ & $\mathrm{N} / \mathrm{A}$ & $\mathrm{N} / \mathrm{A}$ & N/A \\
\hline & & 4 & 5 & PFMR4A $0 \mathrm{nM}$ & $\mathrm{N} / \mathrm{A}$ & $\mathrm{N} / \mathrm{A}$ & $\mathrm{N} / \mathrm{A}$ \\
\hline 20 & 72 & 8 & 5 & PFMR4A $50 \mathrm{nM}$ & $\mathrm{N}$ & $\mathrm{N} / \mathrm{A}$ & 4 \\
\hline \multirow[t]{6}{*}{21} & 58 & 3 & 5 & KSFM/M199 & $\mathrm{Y}$ & $\mathrm{N}$ & Benign \\
\hline & & 3 & 5 & PFMR4A $10 \mathrm{nM}$ & $\mathrm{Y}$ & $\mathrm{N}$ & Benign \\
\hline & & 5 & 5 & PFMR4A $50 \mathrm{nM}$ & $\mathrm{N}$ & $\mathrm{N}$ & Benign \\
\hline & & 5 & 5 & PFMR4A 0 nM & $\mathrm{N}$ & $\mathrm{N}$ & Benign \\
\hline & & 2 & 5 & PFMR4A $50 \mathrm{nM}$ & $\mathrm{N}$ & $\mathrm{N} / \mathrm{A}$ & 3 \\
\hline & & 2 & 5 & PFMR4A 0 nM & $\mathrm{Y}$ & $\mathrm{N} / \mathrm{A}$ & 3 \\
\hline \multirow[t]{2}{*}{22} & 63 & 10 & 5 & PFMR4A $50 \mathrm{nM}$ & $\mathrm{N}$ & N/A & 3 \\
\hline & & 9 & 5 & PFMR4A 0 nM & $\mathrm{Y}$ & $\mathrm{N} / \mathrm{A}$ & 3 \\
\hline \multirow[t]{3}{*}{23} & 55 & 8 & 1 & PFMR4A $+\mathrm{Ctrl}^{8}$ & $\mathrm{~N}$ & $\mathrm{~N}$ & 3/Benign \\
\hline & & 6 & 1 & PFMR4A + 5 uM PL $^{9}$ & $\mathrm{~N}$ & $\mathrm{~N}$ & 3/Benign \\
\hline & & 6 & 1 & PFMR4A + $10 \mathrm{uM} \mathrm{PL}^{10}$ & $\mathrm{Y}(\mathrm{N}$ in benign glands) & $\mathrm{N}$ & 3/Benign \\
\hline \multirow[t]{4}{*}{24} & 52 & 4 & 5 & KSFM/M199 & $\mathrm{N}$ & $\mathrm{Y}$ & Benign \\
\hline & & 4 & 5 & PFMR4A $10 \mathrm{nM}$ & $\mathrm{Y}$ & $\mathrm{N}$ & Benign \\
\hline & & 4 & 5 & PFMR4A $50 \mathrm{nM}$ & $\mathrm{N}$ & $\mathrm{N}$ & Benign \\
\hline & & 8 & 5 & PFMR4A $50 \mathrm{nM}$ & $\mathrm{N}$ & $\mathrm{N} / \mathrm{A}$ & 3 \\
\hline \multirow[t]{4}{*}{25} & 58 & 4 & 5 & KSFM/M199 & Y & $\mathrm{Y}$ & Benign \\
\hline & & 5 & 5 & PFMR4A $10 \mathrm{nM}$ & $\mathrm{Y}$ & $\mathrm{Y}$ & Benign \\
\hline & & 6 & 5 & PFMR4A $50 \mathrm{nM}$ & $\mathrm{N}$ & $\mathrm{N}$ & Benign \\
\hline & & 8 & 5 & PFMR4A $50 \mathrm{nM}$ & $\mathrm{N}$ & $\mathrm{N} / \mathrm{A}$ & 4 \\
\hline \multirow[t]{6}{*}{26} & 76 & 6 & 1 & PFMR4A + Ctrl & $\mathrm{N}$ & $\mathrm{N}$ & Benign \\
\hline & & 6 & 1 & PFMR4A + 5 uM PL & $\mathrm{N}$ & $\mathrm{N}$ & Benign \\
\hline & & 6 & 1 & PFMR4A + 10 uM PL & $\mathrm{N}$ & $\mathrm{N}$ & Benign \\
\hline & & 4 & 1 & PFMR4A + Ctrl & $\mathrm{N}$ & $\mathrm{N} / \mathrm{A}$ & 3 \\
\hline & & 5 & 1 & PFMR4A + 5 uM PL & $\mathrm{Y}$ & $\mathrm{N} / \mathrm{A}$ & 3 \\
\hline & & 5 & 1 & PFMR4A + 10 uM PL & $\mathrm{Y}$ & $\mathrm{N} / \mathrm{A}$ & 3 \\
\hline \multirow[t]{4}{*}{27} & 67 & 2 & 2 & PFMR4A $50 \mathrm{nM}$ & $\mathrm{N}$ & $\mathrm{N} / \mathrm{A}$ & 4 \\
\hline & & 2 & 3 & PFMR4A $50 \mathrm{nM}$ & $\mathrm{N}$ & $\mathrm{N} / \mathrm{A}$ & 4 \\
\hline & & 2 & 4 & PFMR4A $50 \mathrm{nM}$ & $\mathrm{N}$ & $\mathrm{N} / \mathrm{A}$ & 4 \\
\hline & & 14 & 5 & PFMR4A $50 \mathrm{nM}$ & $\mathrm{N}$ & $\mathrm{N} / \mathrm{A}$ & 4 \\
\hline \multirow[t]{2}{*}{28} & 55 & 3 & 5 & PFMR4A $50 \mathrm{nM}$ & $\mathrm{N}$ & $\mathrm{N}$ & Benign \\
\hline & & 3 & 5 & PFMR4A $50 \mathrm{nM}$ & $\mathrm{N}$ & $\mathrm{N} / \mathrm{A}$ & 3 \\
\hline \multirow[t]{2}{*}{29} & 50 & 3 & 5 & PFMR4A $50 \mathrm{nM}$ & $\mathrm{N}$ & $\mathrm{N}$ & Benign \\
\hline & & 3 & 5 & PFMR4A $50 \mathrm{nM}$ & $\mathrm{N}$ & $\mathrm{N} / \mathrm{A}$ & 3 \\
\hline 30 & 72 & 12 & 5 & PFMR4A $50 \mathrm{nM}$ & $\mathrm{N}$ & $\mathrm{N} / \mathrm{A}$ & 5 \\
\hline
\end{tabular}

${ }^{1}$ Column denotes whether more than $25 \%$ of the corresponding tissue slices exhibited luminal epithelial or cancer cell degeneration $(\mathrm{Y}=\mathrm{yes}, \mathrm{N}=\mathrm{no}, \mathrm{N} / \mathrm{A}=$ not applicable).

${ }^{2}$ Column denotes whether more than $25 \%$ of the corresponding tissue slices exhibited basal cell hyperproliferation $(Y=y e s, N=$ no, $N / A=n o t$ applicable)

${ }^{3}$ Complete PFMR-4A + 10 nM R1881

${ }^{4}$ Complete PFMR-4A + 50 nM R1881

${ }^{5}$ Complete PFMR-4A + $100 \mathrm{nM}$ R1881

${ }^{6} \mathrm{KSFM} / \mathrm{M} 199+1 \mathrm{nM}$ DHT + antibiotic/antimycotic

${ }^{7}$ Complete PFMR-4A + 0 nM R1881 (0.05\% ethanol control)

${ }^{8}$ Complete PFMR-4A + $50 \mathrm{nM}$ R1881 + vehicle control (0.1\% DMSO)

${ }^{9}$ Complete PFMR-4A $+50 \mathrm{nM}$ R $1881+5 \mu \mathrm{M}$ piperlongumine

${ }^{10}$ Complete PFMR-4A + $50 \mathrm{nM}$ R $1881+10 \mu \mathrm{M}$ piperlongumine

${ }^{11}$ The Gleason grade is listed for TSCs with predominantly malignant histology; some benign glands may be admixed. 
Table S2. Prevalence of histological patterns in prostate TSCs cultured for 5 days.

\begin{tabular}{|c|c|c|c|c|c|}
\hline & Medium & $\begin{array}{l}\text { Luminal } \\
\text { degeneration }>\mathbf{2 5 \%}{ }^{1}\end{array}$ & $\begin{array}{l}\text { Basal hyperproliferation } \\
>25 \%\end{array}$ & Both & Neither \\
\hline \multirow[t]{4}{*}{ Benign } & KSFM/M199+1nM DHT ${ }^{3}$ & $67 \%$ (4/6 specimens) & $83 \%(5 / 6)$ & $50 \%(3 / 6)$ & $0 \%(0 / 6)$ \\
\hline & PFMR4A + 10nM R1881 ${ }^{4}$ & $100 \%$ (6/6 specimens) & $50 \%(3 / 6)$ & $50 \%(3 / 6)$ & $0 \%(0 / 6)$ \\
\hline & PFMR4A + 50nM R1881 & $23 \%$ (3/13 specimens) & $8 \%(1 / 13)$ & $8 \%(1 / 13)$ & $79 \%(10 / 13)$ \\
\hline & PFMR4A + 0nM R1881 & $66 \%$ (2/3 specimens) & $0 \%(0 / 3)$ & $0 \%(0 / 3)$ & $33 \%(1 / 3)$ \\
\hline \multirow[t]{2}{*}{ Cancer } & PFMR4A + 50nM R1881 & $0 \%(0 / 14$ specimens $)$ & $\mathrm{N} / \mathrm{A}$ & $\mathrm{N} / \mathrm{A}$ & $\mathrm{N} / \mathrm{A}$ \\
\hline & PFMR4A + 0nM R1881 & $75 \%$ (3/4 specimens) & N/A & N/A & N/A \\
\hline
\end{tabular}

${ }^{1}$ Column denotes what percentage of specimens tested under the corresponding culture conditions had greater than $25 \%$ luminal epithelial or cancer cell degeneration.

${ }^{2}$ Column denotes what percentage of specimens tested under the corresponding culture conditions had greater than $25 \%$ basal cell hyperproliferation.

${ }^{3}$ KSFM/M199 + $1 \mathrm{nM}$ DHT + antibiotic/antimycotic

${ }^{4}$ Complete PFMR-4A + 10 nM R1881

${ }^{5}$ Complete PFMR-4A + 50 nM R1881

${ }^{6}$ Complete PFMR-4A + 0 nM R1881 (0.05\% ethanol control) 
Appendix 2.

AACR-Prostate Cancer Foundation Advances in Prostate Cancer Research, San Diego, CA, January 2014

Abstract Title: Combining ex vivo culture and tumorgraft models for the benign and malignant human prostate

Authors: Sophia Maund, Rosalie Nolley, and Donna Peehl

Background: Progress has been made in the development and characterization of in vivo tumorgraft models for primary prostate cancer in which thin, precision-cut slices of tissue are implanted under the renal capsules of immunodeficient mice. Tumorgrafts accurately recapitulate low-grade, high-grade, and castration-resistant disease states and have been shown to predict drug responses in other tumor types. Precision-cut slices allow generation of relatively large numbers of grafts from the same specimen, enhancing reproducibility and recapitulating disease heterogeneity. However, prostatectomy and mouse surgery schedules pose constraints. The model will benefit from extending the time between slicing and engraftment not only by relieving time constraints, but also by allowing experimental manipulation pre-implantation. We have optimized a tissue slice culture (TSC) system that maintains viability of benign and malignant primary human prostate tissue in vitro for 5 days. Here we have begun to explore the use of TSCs in expanding the experimental flexibility and potential of the tumorgraft model.

Methods: Engraftment rate, histology, and viability were compared in grafts of both benign and tumor tissue slices implanted directly post-slicing to those implanted after culturing as TSCs for 3-4 days in vitro. Slices were collected for evaluation after one month in vivo. Experimental manipulations of TSCs pre-implantation were initiated, including evaluation of lentiviral tropism for potential in vivo tumorgraft imaging.

Results and Conclusions: Grafts from benign and malignant tissue implanted immediately postslicing or after culturing as TSCs for 3-4 days presented similar engraftment rates, histological maintenance, and viability after one month in vivo. Grafts derived from TSCs retained an appropriate immunophenotype, showing preservation of cellular structure and function. These results show that TSCs may be successfully combined with the tumorgraft model, allowing time for storage and/or experimental manipulation of primary tissue in vitro pre-implantation. Preliminary studies of viral infection of TSCs suggest that intact benign and malignant tissue slices non-specifically take up lentivirus, and may thereby be labeled with GFP and/or luciferase for in vivo imaging post-engraftment.

Acknowledgements: This work was supported by the Department of Defense Prostate Cancer Research Program Postdoctoral Training Award W81XWH-13-1-0268 
Appendix 3.

SOPHIA L. MAUND, Ph.D.

257 Webster Street, Palo Alto, CA 94301

(336) 473-1044•sophia.maund@gmail.com

EDUCATION

Stanford University, Stanford, CA

Postdoctoral Fellowship

Advisor: Dr. Donna Peehl

Oct 2011 - Nov 2014

Wake Forest University School of Medicine, Winston-Salem, NC

Ph.D., Cancer Biology

Advisor: Dr. Scott Cramer

May 2011

Pomona College, Claremont, CA

B.A., Biology

Advisor: Dr. Daniel Martinez

May 2005

Study Abroad Program: University of Melbourne, Melbourne, Australia

Fall 2003

\section{FELLOWSHIPS, GRANTS \& AWARDS}

Department of Defense Prostate Cancer Research Program Postdoctoral Fellowship

$2013-2014$

Stanford University, Stanford, CA

Helena Anna Henzl-Gabor Young Women in Science Fund for Postdoctoral Scholars

$2012-2013$

Travel Grant, Stanford University, Stanford, CA

NIH Postdoctoral Fellow Training Grant, 5T32DK7217-36

$2011-2013$

Stanford University, Stanford, CA

Lucy Robbins Fellowship

$2009-2010$

Wake Forest University School of Medicine, Winston-Salem, NC

- In recognition of outstanding academic and research expertise, demonstrated leadership, outstanding interpersonal skills, and a commitment to the ideals of excellence in academic research.

Alumni Student Travel Award

$2009-2010$

Wake Forest University Graduate School of Arts and Sciences, Winston-Salem, NC

American Foundation for Aging Research GlaxoSmithKline Grant

$2008-2010$

Wake Forest University School of Medicine, Winston-Salem, NC

Graduate Student Poster Award, $2^{\text {nd }}$ Place

Aug 2010

Wake Forest University School of Medicine, Winston-Salem NC

Edward A. Smuckler Memorial Pathobiology of Cancer Workshop

July 2008

American Association for Cancer Research, Snowmass, CO.

- Week-long workshop funded by AACR and the NCI, taught by expert pathologists. International applicants competitively reviewed and selected.

Director's Award, Department of Cancer Biology, Wake Forest University School of Medicine, 2005 - 2009 Winston-Salem, NC

- Fellowship for graduate student excellence.

NIH Training Grant 5T32CA079448-10, Department of Cancer Biology, Wake Forest University 2005 - 2010 School of Medicine, Winston-Salem, NC

M.H. Sherman Scholarship, Pomona College, Claremont, CA $2004-2005$

Reeves Scholarship, Pomona College, Claremont, CA 2003 - 2004

Research Experience for Undergraduates Grant, Department of Biology, Pomona College, 2002 - 2003 Claremont, CA

\section{PUBLICATIONS IN PEER-REVIEWED JOURNALS}

Maund, S.L., Nolley, R., and Peehl, D. (2014) Optimization and comprehensive characterization of a faithful tissue culture model of the benign and malignant human prostate. Laboratory Investigation. 94(2):208-221. 


\section{PUBLICATIONS IN PEER-REVIEWED JOURNALS (continued)}

Maund, S.L., Shi, L., and Cramer, S.D. A role for Interleukin-1 alpha in the 1,25 dihydroxyvitamin $\mathrm{D}_{3}$ response in mammary epithelial cells. PLoS One. 8(11): e81367. DOI 10.1371/journal.pone0081367

Belardi, B., de la Zerda, A., Spiciarich, D.R., Maund, S.L., Peehl, D.M., and Bertozzi, C.R. (2013) Imaging the glycosylation state of cell surface glycoproteins using two-photon fluorescence lifetime imaging microscopy. Angewandte Chemie International Edition. DOI 10.1002/anie.201307512

Maund, S.L., Barclay, W.W., Hover, L.D., Axanova, L.S., Sui, G., Hipp, J., Fleet, J.C., Thorburn, A., and Cramer, S.D. (2011) Interleukin-1 alpha mediates the anti-proliferative effects of 1,25 dihydroxyvitamin $\mathrm{D}_{3}$ in prostate progenitor/stem cells. Cancer Research. June 8, doi: 10.1158/0008-5472.CAN-10-2160

Maund, S.L. and Cramer, S.D. (2010) The tissue-specific stem cell as a target for chemoprevention. Stem Cell Reviews and Reports. 7(2): 307.

Barclay, W.W., Axanova, L.S., Chen, W., Romero, L. Maund, S.L., Soker, S., Lees, C., Cramer, S.D. (2008). Characterization of Adult Prostatic Progenitor/Stem Cells Exhibiting Self-Renewal and Multilineage Differentiation. Stem Cells. 26: 600-610.

\section{EDITORIAL/COMMENTARY}

Sophia L. Maund and Scott D. Cramer (2011). Pancreatic cancer with Nest-in tendencies. Cell Biology \& Therapy. 11(6): 559-561.

\section{BOOK CHAPTERS}

Sophia L. Maund and Scott D. Cramer (2011). The role of vitamin D in the prevention and treatment of prostate cancer. Prostate Cancer - From Bench to Bedside, Phillip E. Speiss, (Ed.), ISBN: 978-953-307-331-6, InTech.

Sophia L. Maund and Scott D. Cramer (2009). Translational implications of stromal-epithelial interactions in prostate cancer and the potential role of prostate cancer stem/progenitor cells. The Handbook of Cell Signaling, second edition. Ralph Bradshaw and Edward Dennis eds. San Diego, CA, Elsevier Inc. 27732782.

\section{INVITED ORAL PRESENTATIONS}

"Optimization and applications of a tissue slice culture model for the normal and malignant human Feb 2012 prostate" American Association for Cancer Research Special Conference: Advances in Prostate Cancer Research, Orlando, FL.

"Current topics in prostate cancer treatment and research"

Aug 2009

The Wellness Community, Walnut Creek, CA

"Topics in prostate cancer prevention, treatment, and lifestyle"

Cook Medical, Winston-Salem, NC

"Current topics in prostate cancer prevention, treatment, and lifestyle"

Mar 2009

Best Health Wellness Center, Winston-Salem, NC

"Investigating a mechanism of vitamin D-induced differentiation of prostatic progenitor cells"

Nov 2008

American Foundation for Aging Research GlaxoSmithKline Aging Research Symposium, Raleigh, NC.

"Using prostate stem cells to study vitamin D-mediated chemoprevention of prostate cancer" Pomona College, Claremont, CA

\section{POSTER ABSTRACTS}

"Combining ex vivo and tumorgraft models of the benign and malignant human prostate" Jan 2014 Maund, S.L., Nolley, R., Peehl, D.M. American Association for Cancer Research-Prostate Cancer Foundation Conference on Advances in Prostate Cancer Research, San Diego, CA. 


\section{POSTER ABSTRACTS (continued)}

"Expanding the experimental potential of a novel ex vivo model for primary human prostate cancer" April 2013 Maund, S.L., Nolley, R., Peehl, D.M. American Association for Cancer Research Annual Meeting, Washington, D.C.

"Optimization and applications of a tissue slice culture model for the normal and malignant human

Feb 2012 prostate" Maund, S.L., Nolley, R., Santos, J. and Peehl, D. American Association for Cancer Research Special Conference: Advances in Prostate Cancer Research, Orlando, FL.

"A novel role for interleukin-1 alpha in 1,25 dihydroxyvitamin $\mathrm{D}_{3}$ signaling" Maund, S. L.,

Oct 2010 Barclay, W.W., Hover, L.D., Axanova, L.S., Sui, G., and Cramer, S.D. American Foundation for Aging Research and GlaxoSmithKline Symposium on the Biology of Aging, Raleigh, NC.

"Interleukin-1 alpha is a critical mediator of 1, 25 dihydroxyvitamin D-induced growth inhibition

Oct 2009 of prostatic progenitor cells" Maund, S. L., Barclay, W.W., Hover, L.D., Axanova, L.S., Sui, G., and Cramer, S.D. $14^{\text {th }}$ Workshop on Vitamin D, Brugges, Belgium.

"Interleukin-1 alpha is a critical mediator of 1, 25 dihydroxyvitamin D-induced growth inhibition of Jan 2009 prostatic progenitor cells" Maund, S.L., Barclay, W.W., Sui, G., and Cramer, S.D. AACR

Advances in Prostate Cancer Research, San Diego, CA.

"Elucidating a mechanism of vitamin D-mediated differentiation of prostatic progenitor cells"

Nov 2008

Maund, S.L., Barclay, W.W., Sui, G., and Cramer, S.D. American Foundation for Aging

Research and GlaxoSmithKline Aging Research Symposium, Raleigh, NC.

"Elucidating a mechanism of vitamin D-mediated differentiation of prostatic progenitor cells"

Oct 2008

Maund, S.L., Barclay, W.W., Sui, G., and Cramer, S.D. Cancer Biology Training Consortium

Chair and Directors Retreat and Annual Meeting, Park City, UT.

"Interleukin-1 alpha mediates vitamin D-induced differentiation of prostatic progenitor cells" Maund, S.L., Barclay, W.W., Sui, G., and Cramer, S.D. AACR Pathobiology of Cancer Workshop, Snowmass, CO.

\section{RESEARCH EXPERIENCE}

\section{Postdoctoral scholar (Stanford University)}

Project: Establishing an ex vivo tissue slice culture model of renal cell carcinoma

Jan 2014 - present

Investigators: S.L. Maund, D.M. Peehl

Project: Combining tissue slice culture and tumorgraft models of primary prostate cancer

Investigators: S.L. Maund, D.M. Peehl

Project: MALDI-MS spatial expression mapping of drug response in prostate tissue slice cultures

Investigators: S.L. Maund, D.M. Peehl, R. Drake

Project: Glycoproteomic profiling of prostate tissue slice cultures for biomarker discovery

Investigators: S.L. Maund, D. Spiciarich, D.M. Peehl, C. Bertozzi

Project: Development and implementation of a tissue slice culture model of prostate cancer

Investigators: S.L. Maund, D.M. Peehl

Project: PARP inbibition and the DNA damage response in prostate cancer tissue slice cultures

Investigators: S.L. Maund, T. Hallstrom, D.M. Peehl, M. Laiho

Graduate student researcher (Wake Forest University School of Medicine)

Several projects studying topics in prostate and breast cancer

Thesis work: Characterization of cellular and genomic effects of 1,25 dibydroxyvitamin $\mathrm{D}_{3}$ in prostate progenitor/stem cells

Investigators: S.L. Maund, S.D. Cramer

\section{Undergraduate researcher (Pomona College)}

Project: Molecular phylogeny of Hydra

June 2013 - present

May 2012 - present

Feb 2012 - present

Thesis work: Developmental genetics of axis formation in morphologies of the cnidarian Podocoryne Carnea

$2003-2004$

Investigators: S.L. Maund, D.E. Martinez

Project: Phylogenetic streamlining of introns

$2003-2005$

Aug 2005 - July 2011

May 2006 - May 2011

Oct 2011 - Dec 2013

Oct $2011-$ Oct 2012

Investigators: S.L. Maund, N. Schisler

$2002-2003$ 


\section{TEACHING EXPERIENCE}

Instructor:

UC Berkeley Extension, San Francisco, $C A$

"Cell Biology" (MCELLBIX116, undergraduate)

$2013-2014$

\section{Guest lecturer:}

UC Berkeley, Berkeley, $C A$

"General Biology" (BIO1A, undergraduate)

Mar 2012

Stanford University, Stanford, CA

"Topics in Microbiology" (MI285, undergraduate and graduate)

Jan 2012

Winston Salem State University, Winston-Salem, NC

"Pharmacology of Physical Therapy" (PHT6203, graduate)

Sept 2010

"Biochemistry" (BIO3346, undergraduate)

Feb - Mar 2009

\section{Co-instructor:}

Wake Forest University, Winston-Salem, NC

"Cell Biology of Cancer" (CABI704, graduate)

$2008 \& 2009$

"Biotechniques" (pre-fall curriculum for incoming graduate students)

Aug 2008

\section{Mentor:}

Wake Forest University, Winston-Salem, NC

Laura Hover (undergraduate student)

$2008-2010$

- Trained student in laboratory techniques, experimental design, scientific writing, and oral presentation.

Coached student through graduate school applications and interviews. Hover is currently pursuing a

Ph.D. in Cancer Biology from Vanderbilt University.

Philna Joubert (high school student)

- Trained student in laboratory techniques, experimental design and oral presentation through the Center for Excellence in Research, Teaching, and Learning enrichment program for high school students.

\section{Community educator:}

- Explained topics in cancer research, prevention, treatment, and lifestyle to cancer patients and caregivers in North Carolina and California (see Invited Oral Presentations).

\section{Tutor:}

Wake Forest University, Winston-Salem, NC

- Selected by graduate program director to tutor struggling graduate students in biochemistry, 2008 - 2009 carcinogenesis, DNA damage and repair.

\section{INSTITUTIONAL SERVICE}

Academic Curriculum Committee member, Department of Cancer Biology, Wake Forest

University School of Medicine, Winston-Salem, NC

- Influenced changes in the departmental curriculum to maintain its competitive standing

Graduate Student Research Day Chair, Department of Cancer Biology, Wake Forest University

School of Medicine, Winston-Salem, NC

- Planned and ran the symposium, invited and hosted distinguished guest scientist.

Honor Code Panel member, Wake Forest University Graduate School of Arts and Sciences,

Winston-Salem, NC

- Nominated by faculty, served to maintain ethical academic standards. 


\section{INSTITUTIONAL SERVICE (continued)}

Cancer Biology Training Consortium Chair and Directors' Retreat and Annual Meeting representative, Park City, UT

- Nominated by faculty, contributed ideas and implemented changes to departmental curriculum.

Discussions published in "Ph.D. Training in Cancer Biology" Cancer Research 2008 68: 9122-9124.

Recruitment committee member, Department of Cancer Biology, Wake Forest University School of Medicine, Winston-Salem, NC

- Evaluated visiting student and faculty candidates.

\section{PROFESSIONAL AFFILIATIONS}

American Association of Cancer Research (AACR) and AACR Women in Cancer Research, 2006 - Present Associate member

Sigma Xi, The Scientific Research Society, Associate member

2005 - Present

\section{VOLUNTEER \& COMMUNITY ACTIVITIES}

Stanford University Postdoctoral Association member

$2011-2014$

- Served on committee for organizing teaching resources for Stanford postdocs.

Ambassador for North Carolina DNA Day

- Taught high school students about genetics and discussed science education and careers.

Graduate School Orientation volunteer

Aug 2006-2009

- Panelist for "Fundamentals of Scientific Integrity"

- Trained new students in laptop and software usage

- Served as a resource for acclimation to graduate school (Matching Matriculants and Returning Students program)

Organizer and recruiter for Graduate School Forum

- Helped plan and execute a symposium for graduate students on professional development and career advice.

Scientific photographer: Research as Art

- Photographs taken in the lab, translate the beauty of science to the public

- Displayed 25 original photographs in a gallery setting

- Permanent exhibit at Wake Forest University Graduate School of Arts and Sciences 